\title{
Smaller Mountain Volcanoes on Mars: Cinder Cones
}

\author{
Khaled Ak Ouda* and Nadia Af Sharara
}

Geology Department, Faculty of Science, Assiut University, Assiut 71516, Egypt

*Corresponding author: Khaled Ak Ouda, Geology Department, Faculty of Science, Assiut University, Assiut 71516, Egypt

\section{Abstract}

The present investigation concerns with the satellite remote sensing study (via Google Mars) of topography, morphology and relative age concept of smaller mountain volcanoes which are formed on the surface of Mars by pyroclastic materials accumulating around a central vent (cinder or scoria cones). The study reveals the recognition of two different morphological types of cinder cones of different relative ages:

Older, Simple Cinder Cones (SCC) characterized by a narrow peripheral vent, a closed central vent, and a shallow summit crater without post-cone eruption of parasitic volcanic lava at the bottom of summit; and

younger, Modified Cinder Cones (MCC) characterized by having an open central vent beside a wide peripheral vent, a larger and deeper bowel-shaped summit crater which extends below the ground surface level and shows the presence of a younger parasitic volcanic phase made up of lava dome at the bottom floor of the summit crater. Both types occur independently or as parasitic landforms at the bottom floor of larger pre-existing calderas and along the flanks of some shield volcanoes. When occurring independently they form isolated massive fields in the lowlands of the northern hemisphere where they show evidence of erosion with varying rates, whereas in the highlands of the southern hemisphere they occur in clusters with no or little rate of erosion. This would suggest that cinder cones are not synchronous on Mars. The study contributes to improved understanding of the volcanic activity on Mars.

Keywords: Remote sensing; Mars; smaller mountain volcanoes; cinder (scoria) cones

\section{Introduction}

Cinder cones are the most common subaerial volcano type on Earth [1,2]. They are commonly found on the flanks of shield volcanoes, stratovolcanoes (composite volcanoes) and calderas. For example, geologists have identified nearly 100 cinder cones on the flanks of Mauna Kea, a shield volcano located on the island of Hawaii (these cones are also referred to as scoria cones and cinder and spatter cones) [3]. Cinder cones are also the smallest type of the mountain volcanoes, with a height generally less than 300 meters on Earth. They usually form clusters of isolated cone field either on a flat surface or as parasitic cones upon the flanks of major volcanoes $[1,4]$.

The terrestrial cones have very steep slopes, up to 35 degrees, although older eroded cones typically have gentler slopes, from 15 to 20 degrees. Cinder cones have straight sides and very large summit craters, with respect to their relatively small edifices. On average their basal diameter is
$800 \mathrm{~m}(0.25-2.5 \mathrm{~km})$, volume is $40 \times 106 \mathrm{~m} 3$, and spatial density is $0.03-0.5$ cone/ $\mathrm{km} 2[2,5]$. The slope of flanks is reaching $30^{\circ}$. Fresh cinder cones' crater to cone diameter relation is 0.40 ; cone height to basal diameter ratio is 0.18 (1:5). The physical dimensions of cinder cones decrease with time because of the erosion [6], and therefore, also the crater to cone diameter relation is lower in older cinder fields.

Measurements of cone shape and distribution have been performed in three volcano cone fields (Mauna Kea, Hawaii; Mt. Etna, Italy; Kilimanjaro, Tanzania) and three platform cone fields (San Francisco Mtn., Ariz.; Paricutin region, Mexico; Nunivak Island, Alaska). According to Settle [1] modal average values of cone basal diameter are on the order of 300 to $400 \mathrm{~m}$ within volcano cone fields and 900 to $1000 \mathrm{~m}$ within platform cone fields. Cone height/diameter ratios are generally smaller within the platform cone fields. Variations in cone shape cannot be directly attributed 
to different eruption conditions; however, since cone morphometry is also a function of weathering environment and exposure age.

Cinder cones are formed by simultaneous or alternating explosions and mafic lava effusion, mostly (but not always) by monogenetic (single) eruptive episodes [7]. They are common in subduction zones, in continental rift zones, and at some central volcanoes $[4,7,8]$. Cinder cone fields are more abundant than shield fields on Earth [9]. Terrestrial cinder cones are typically built in 12 days, regardless of size (with a range from 1 day to 15 years; median, 30 days) [2]. The volume of terrestrial cinder cones is thought to be directly proportional to the depth of their magma source [5]. They originate from explosive, strombolian, and sometimes Hawaiian, sub-plinian, or phreatomagmatic eruptions of low-viscosity magma [4]. Sometimes they originate from fissure eruption, like at volcanic fields of Laki (Iceland) and Tolbachik (Kamchatka, Russia).

A much work has been focused on the terrestrial cinder cones, but little has been done on those smaller mountain volcanoes on the surface of Mars. The present investigation is concerned with the Remote sensing study of the topography, morphology and relative age concept of different types of cinder cones on the surface of Mars.

\section{Previous Related Work}

Based on satellite images it was suggested by Wood [5] that cinder cones might occur on other terrestrial bodies in the solar system too. Wichman and Schultz [10] showed a field of 4 larger cinder cones, each of which is $2-5 \mathrm{~km}$ in size, and they are located near the edge of the cratered uplands. Like large cinder cones on Earth, most show a lop-sided, horse-shoe like pattern. Wilson and Head [11] showed one likely group of small volcanic cones on Mars. The features of the cones are all less than a kilometer in size, and they are located in the northern lowlands. Each shows a clear central pit, and several lie on or along older faults. They are similar in size to Earth cinder cones, but the central pits are larger. Like Earth cones, they mark the sites of small explosive eruptions.

Recently, cones interpreted as cinder cones on Mars thought to form by explosive volcanism have been detected in the following regions: the southern flank of Pavonis Mons [12,13], Hydraotes Chaos [14], Syria Planum [15], SW Utopia Planitia [16], the volcanic field Ulysses Colles in Tharsis [17]. The Martian equivalents of terrestrial cinder cones were reported as parasitic cones on the flanks of large volcanoes [17-19] or as cone clusters forming volcanic fields $[13,15,16,19]$.
Although the interpretation of these cones as cinder cones was mainly based on their morphological similarity with terrestrial analogues, no detailed investigation of their morphometry was performed to support such conclusion, with a partial exception for the Hydraotes Colles cone field [13] and the Ulysses Colles cone field $[16,19,20]$. Lanz and Saric [21] have studied a large cone field in SW Elysium Planitia that shows unique characteristics that have, as yet, not been described elsewhere on Mars. According to them pitted cones and cone fields are quite common on Mars and the Elysium Planitia region where they have been mainly interpreted as pseudocraters. The cones in the study area differ from cones elsewhere on Mars in morphology, geologic setting, and their assemblage with pitted ridges as well as their close association to Aeolis Planum-Medusae Fossae Formation (MFF) material.

Lanz et al. [15] analyzed a small cone field in SW Utopia Planitia that shows striking similarities to volcanic rift zones on Earth. This is of particular interest as the study area lies off any of the volcanic centers of Mars in the northern hemisphere lowlands and is embedded in Amazonianaged Vastitas Borealis (the largest lowland region of Mars) formation material. The most striking characteristics are

a. A set of broad eruptive fissures showing signs of ongoing extension during cone formation,

b. Parallel dike swarms,

c. Magmatic intrusions, and

d. A number of lava flows that can be seen to have erupted from the fissures and pitted cones aligned along fissures and dikes. Based on stratigraphic analyses and cratering statistics Lanz et al. [15] believe that their study area might represent a "geologic window" to volcanic activity in the northern lowlands pre-dating the extensive resurfacing by VBF units.

Brož and Hauber [16] considered the cinder cones in Ulysses Fossae region in Tharsis on Mars to be probably formed between 0.44 and 1.5 Ga years ago. According to these authors, the mean basal diameter for cones in Ulysses Colles is $2.3 \mathrm{~km}(1-3.9 \mathrm{~km})$. This is about 2.6 times larger than the basal diameter of terrestrial cinder cones. The crater diameter for the cones ranges from 185 to $1,185 \mathrm{~m}$, with an average of $650 \mathrm{~m}$. The height of cones is on average $230 \mathrm{~m}$ (64-651 m), Martian cinder cones higher than terrestrial analogs.

Ghent et al. [22] investigated the distinctive distribution and pattern of subkilometer-sized cones in Isidis Planitia, and their relationship to the material that fills the basin.

Citation: Khaled Ak Ouda* and Nadia Af Sharara . Smaller Mountain Volcanoes on Mars: Cinder Cones. Op Acc J Bio Sci \& Res 5(5)-2020. 
They observed that:

a. The cones show uniform size, spacing, and morphology across the entire basin;

b. They have large central depressions (relative to cone basal diameters) that are generally filled in and commonly show layering;

c. Cone chains form highly organized spatial patterns; cones are also found in isolation and in dense fields;

d. Many adjacent chains are parallel, and evenly spaced, creating a pattern that mimics lava flows that have experienced compressional folding;

e. NO flows are associated with the cones;

f. The cones are at least temporally related to basin fill;

g. The basin fill material is largely fine-grained, but with locally indurated layers at shallow depth; and

h. Relationships between cones along a chain show no systematic temporal formation sequence along the chain. They came to the conclusion that the basin was likely inundated by one or more hot, partially welded pyroclastic flows; devolatilization of these flows remobilized volcaniclastic material to form the cones without associated lava flows.

Brož et al. [20] noted that the cinder cones on Mars did not reach the angle of repose, and therefore their morphological shape preserves a record of environmental conditions at the time of eruption and hence preserves information about ejection velocities (if erosional degradation of these relatively young edifices is considered negligible). This offers an opportunity to examine basic parameters controlling cone formation by numerical modeling more deeply.

Broz et al. [19] analyzed the shapes of 28 hypothesized scoria cones in three regions on Mars, i.e., Ulysses and Hydraotes Colles and Coprates Chasma. Most of the studied cones show larger volumes (up to $4.2 \times 109 \mathrm{~m} 3$ ), larger heights (up to $573 \mathrm{~m}$ ), and smaller average slopes. The average slopes of the Ulysses, Hydraotes, and Coprates cones range between $7^{\circ}$ and $25^{\circ}$, and the maximum slopes only rarely exceed $30^{\circ}$. The parameters obtained by these authors for the cones in $\mathrm{HC}$ and $\mathrm{CC}$ show similar distributions which suggest that both fields were created by the same geological process. According to them the cones in UC, which have been interpreted by Brož and Hauber [16] as scoria (cinder) cones, form an independent trend on morphometric graphs and their characteristics differ from those in $\mathrm{HC}$ and CC-the cones are more voluminous and have smaller average slope angles than the cones in the other two regions. The results support the hypothesis that the investigated edifices were formed by low-energy Strombolian volcanic eruptions (named for the Italian volcano Stromboli) and hence are equivalent to terrestrial scoria cones.

Gilichinsky et al. [23] identified 14 potential cinder cones localized mostly in the Chasma Boreale region within the area $79^{\circ}-81^{\circ} \mathrm{N}$ and $261^{\circ}-295^{\circ} \mathrm{E}$. The calculated morphometric parameters showed that the cone average steepness varied from $3.4^{\circ}$ to $11.8^{\circ}$, cone height-to-width ratio varied from 0.025 to 0.12 , and the ratio between surface and basal area of the cone varied from 1.005 to 1.131. The studied cinder cones were classified with respect to the morphometric ratios assuming that larger values correspond to the younger structures.

\section{Method of Study}

This study has been made possible by the use of Google Mars which is a program that allows exploring Mars through official satellite images gathered by different spacecraft orbiting the planet. The program is an application within Google Earth Pro which is currently the standard version of the Google Earth desktop application as of version 7.3.2.5776 (64-bit), Build Date Tuesday, March 5, 2019 12:43:51 AM UTC7.3. The program of Google Mars allows viewers to zoom around the Red Planet in much higher resolution than the simpler browser version and will even render certain locations in 3-D. It includes extremely highresolution images from the Mars Reconnaissance Orbiter's HiRISE camera on the NASA Mars Reconnaissance Orbiter spacecraft, the Context Camera (CTX) on NASA's Mars Reconnaissance Orbiter which offers great details with around 20 feet per pixel, the Narrow Angle Mars Orbiter Camera (MOC) on the NASA Mars Global Surveyor spacecraft, the High Resolution Stereo Camera (HRSC) instrument on the European Space Agency Mars Express spacecraft, the Compact Reconnaissance Imaging Spectrometer for Mars(CRISM) instrument on the NASA Mars Reconnaissance Orbiter spacecraft. Finally, there are many high-resolution panoramic images from various Mars landers, such as the Mars Exploration Rovers, Spirit and Opportunity, that can be viewed in a similar way to Google Street View.

About 100 satellite images of different types of cinder cones on the surface of Mars were carefully examined for resolution, distribution, unique morphology and evidence of volcanic activity. For means of graphical correlation between different types of cones the morphological 
parameters of 45 independent and 15 parasitic cinder cones have been subjected to detailed statistical analyses. To make the graphic comparison possible between different types of cinder cones volcanoes, the electronic profile is rejected and a manual cross section has been made for the independent cinder cones, where selected points of elevation for each cinder cone were chosen along the width of the volcano in the range of 15 or 16 points distributed more or less symmetrically spaced on both sides of the center of summit across the maximum width (basal diameter) of volcano. The results were subjected to the Microsoft Excel 2010 program where a cross-section is drawn representing the topography and topographic elevation of cone flanks, the width of volcano, the maximum depth of summit (below ground surface), the maximum height of the mountain volcano above ground surface (above surroundings) and diameter of the summit are given for each volcano. The morphologic features of the parasitic cinder cones which develop at the bottom surface of some pre-existing large caldera craters (15 parasitic cones) and the parasitic volcanic (lava) domes which erupted at the bottom surface of the deep summit of larger cinder cones (15 parasitic lava domes) are measured by using the electronic profile of Google Mars and the data are discussed and represented graphically. Data of the parasitic cinder cones are correlated with those of the independent ones.

\section{Results and Discussion}

Cinder Cones Volcanoes on Mars

Cinder cones are much common on the surface of Mars and much larger in size than the terrestrial counterparts. They show a much variable width of cone (basal diameter), height of cone, diameter of summit and subsurface depth of summit below ground surface, as well as the presence or absence of second post cinder cone re-eruption of lava at the bottom of the collapsed summit after re-filling of the magma chamber below the central vent of the original cone.

The cones have a maximum width (basal diameter) ranging between $12.2 \mathrm{~km}$ and $134 \mathrm{~km}$; with few cones exceeding $150 \mathrm{~km}$ up to $187 \mathrm{~km}$ in width. The data are much more by 40 to 50 times than those on the Earth $[2,5]$. They have a large summit crater at top of the mountain varying in diameter from $2.25 \mathrm{~km}$ to $32 \mathrm{~km}$ with the exception of one cone has a summit diameter of $44 \mathrm{~km}$. However, the height of cones above the ground surface of Mars is little higher than those of the terrestrial cones. It ranges from $57 \mathrm{~m}$ to $476 \mathrm{~m}$; with a fewer number of cones exceeding a height of $500 \mathrm{~m}$ up to $1566 \mathrm{~m}$. The average percentage of the diameter of summit relative to the width of cone (basal diameter) in different types of cones is $24-25 \%$ while the average percentage of height of cone relative to width of cone is $0.54-0.57 \%$. The cones are either symmetrical or asymmetrical due to building up of pyroclastic materials higher on the downward side of the vent.

The maximum slope of these cones is proportional to the height of cone. It varies greatly due to either variation in size of the different types of cones or to variation of rate of erosion of the same type of cones. In the lowlands of the northern hemisphere the cinder cones occur in isolated fields in which combination of volcanic eruption of cinder cones of varying sizes, shape and age cover vast flat plains particularly near the northern ice -pole (Figure 1a-1e). The smaller cinder cones show evidence of erosion with varying rates leading to variable heights and variable maximum slopes of cones. Those which occur near the northern ice pole are severely eroded cones in which the height of cone varies from $57 \mathrm{~m}$ to $256 \mathrm{~m}$ with an average height of 110.5 $\mathrm{m}$, corresponding to a maximum slope ranging between $2.2 \%$ and $9.65 \%$ with an average maximum slope of 5.3 $\%$. In moderately eroded smaller cones in the northern hemisphere the height of cone varies from $82 \mathrm{~m}$ to 432 $\mathrm{m}$ with an average height of $183.5 \mathrm{~m}$, corresponding to a maximum slope ranging between $10.0 \%$ and $19.1 \%$ with an average value of $13.8 \%$. Those which are weakly eroded in the northern hemisphere are generally few and showing an average height of $194.7 \mathrm{~m}$, corresponding to a maximum slope of $25.2 \mathrm{~m}$. However, in the highlands of the southern hemisphere the small cinder cones occur usually in clusters with no or little rate of erosion (Figure 1f) where the height of cones varies from $87 \mathrm{~m}$ to $583 \mathrm{~m}$ with an average height value of $220 \mathrm{~m}$, corresponding to a maximum slope ranging between $23.0 \%$ and $40.7 \%$ with an average value of 30.35 $\%$.

The larger cinder cones in the lowlands of the northern hemisphere are very weekly eroded to non-eroded, varying in height from $170 \mathrm{~m}$ to $716 \mathrm{~m}$ with most values lying between $298 \mathrm{~m}$ and $536 \mathrm{~m}$, and an average height value of $441.5 \mathrm{~m}$, corresponding to a maximum slope ranging between $10.9 \%$ and $55.95 \%$ with most values lying between $27.3 \%$ and $38.4 \%$ and an average maximum slope of 33.2 $\%$ (Figure 1g-1h). Those which are situated in the highlands of the southern hemisphere show no evidence of erosion although some of them are tectonically disturbed. They are considerably large in size, having a height varying from $378 \mathrm{~m}$ to $1566 \mathrm{~m}$ and with an average value of $748.25 \mathrm{~m}$, corresponding to a maximum slope varying from $27.9 \%$ and $53.8 \%$, and with an average value of $38.85 \%$ (Figure 1 i).

In general, the small-sized cones which have an average 


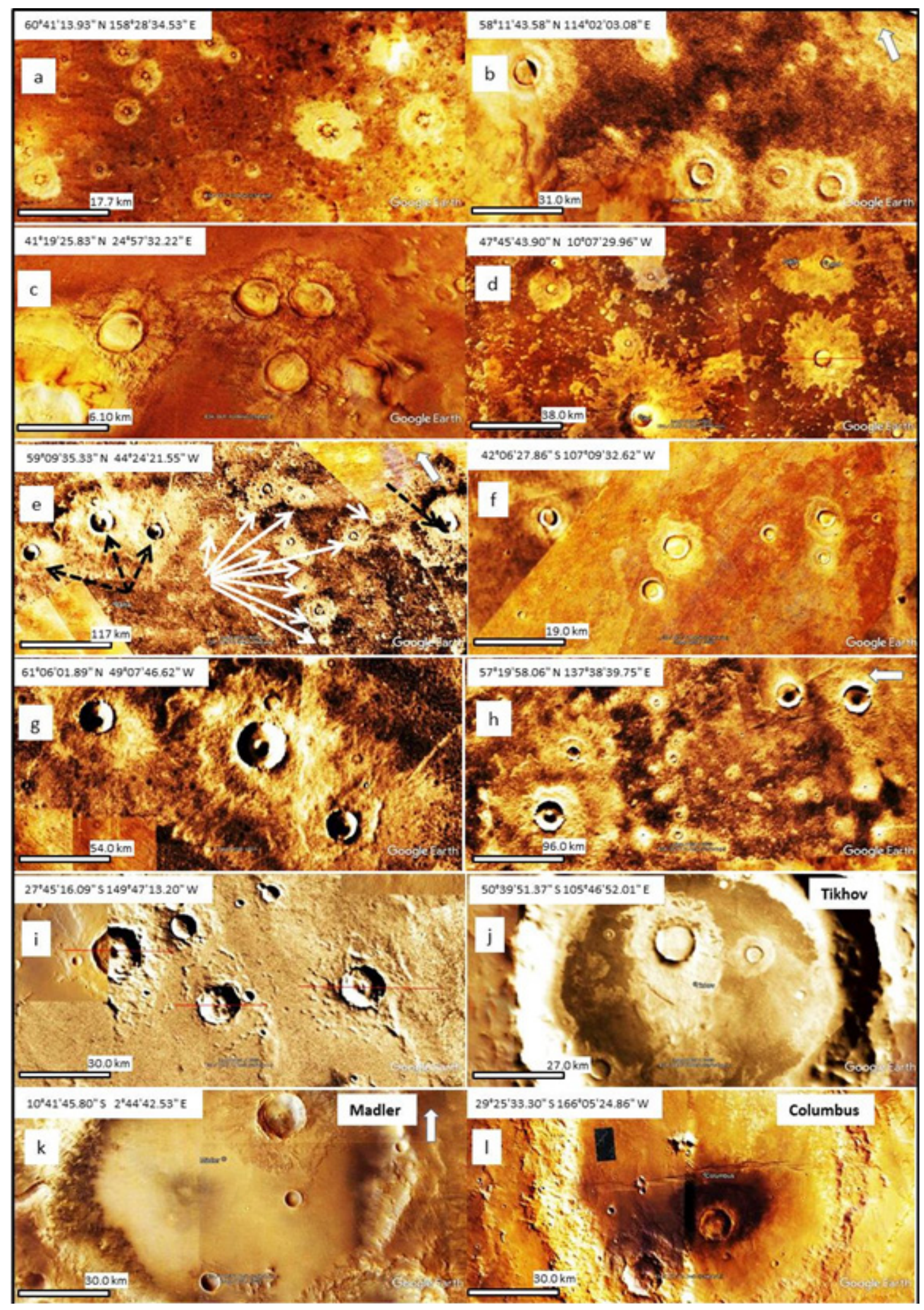

Figure 1: a-d-Volcanic fields made up of dense concentrations of small-sized, Simple Cinder Cones (SCC) in the northern hemisphere of Mars. e- Volcanic fields including combination of small-sized simple cinder cones (continuous arrows) and large-sized modified cones (dotted arrows). $f$-Clusters of simple cinder cones in the southern hemisphere. $g$ - $h$ - Large-sized, Modified Cinder Cones (MCC) erupted inside volcanic fields of smaller simple cinder Cones in the northern hemisphere. $i$ - Clusters of MCC in the southern hemisphere. J-IParasitic cinder cones inside the bottom of larger volcanic craters (calderas) in both the northern (j) and southern hemispheres (k-l). From now and going on, the geographic north lies to the north of the image unless it is shown on the image.

Citation: Khaled Ak Ouda* and Nadia Af Sharara. Smaller Mountain Volcanoes on Mars: Cinder Cones. Op Acc J Bio Sci \& Res 5(5)-2020. 
width (basal diameter) of $31.18 \mathrm{~km}$ attain an average height of $167 \mathrm{~m}$, corresponding to an average maximum slope of $14.58 \%$. Some cones assume a rate of a maximum slope less than $5 \%$ due to severe erosion (ser. 3, 12, 16, 21, 23, 26) near the northern ice pole. The large-sized cones have an average width (basal diameter) of $100.38 \mathrm{~km}$, an average height of $523.33 \mathrm{~m}$ and an average maximum slope of 33.7 $\%$. The difference in maximum slope reflects difference in duration of time of erosion; the severely eroded cones seem to be the oldest cones while the non-eroded cones represent the youngest simple cinder cones [24].

Beside the differences in width, height, diameter of summit and maximum slope between the small-sized and the large-sized cinder cones, there is a fundamental difference between both landforms. The large-sized cones possess a central deep vent beside a wide peripheral vent. The central vent shows in the majority of specimens a younger phase of eruption of viscous lava flows formed as a result of re-filling of the magma chamber below the central vent and leading to the formation of lava domes at the basal floor of the summit crater of the pre-existing cinder cone. All these differences have led to the recognition of two genetically different types of cinder cones on the Martian surface; 1) an older smaller, simple cinder cone with a narrow peripheral vent and a shallow summit crater without post-cone eruption of younger phase of volcanic lava at the bottom of summit (simple cinder cones), and 2) a younger larger modified cinder cone with a central vent beside a wide peripheral vent and a deep bowel-shaped summit crater showing a younger phase of post-cone viscous lava flow from the central vent at the bottom of summit of the pre-existing cone (modified cinder cones).

Both types of cones occur independently either in clusters distributed sporadically in the southern hemisphere of Mars (Figure $1 \mathrm{f}$ and $1 \mathrm{i}$ ) but they are mostly occurring in the form of isolated massive fields particularly in the northern low-lying lands of Mars near the northern ice pole (Figure $1 \mathrm{a}-1 \mathrm{e}$ and $1 \mathrm{~g}-1 \mathrm{~h})$. They also occur commonly as parasitic landforms on the bottom surface of some larger types of collapse calderas (Figure $1 \mathrm{j}$-1l) but they are rarely occurring as parasitic landforms along the flanks of shield volcanoes.

\section{Simple Cinder Cones (SCC)}

These are small, steep-sided volcanic cones with a shallow circular summit and made up almost of pyroclastic material (Figure 2a-2g; Figure 3h-3n; Figure 4a-4g; Figure $5 h-5 n)$. They are found in both low- and highlands, but mostly concentrated in the form of massive fields in the low-lying areas of the northern hemisphere of Mars between latitudes $40^{\circ} \mathrm{N}$ and $76^{\circ} 30^{\prime} \mathrm{N}$. In these areas the fields of simple cinder cones are made up of hundreds of small-sized simple cones and enclosing tenths of clusters of relatively larger modified cinder cones (Figure 1e). In the southern highland hemisphere, the simple cinder cones occur independently as free landform in clusters of few numbers (Figure 1f).

The simple cinder cones occupy two main restricted topographic levels, one level lying between elevations $-3500 \mathrm{~m}$ and $-5000 \mathrm{~m}$ below 0 datum level where most simple cinder cones are represented in the northern lowlands between latitudes $40^{\circ} \mathrm{N}$ and $76^{\circ} 30^{\prime} \mathrm{N}$. The other level lies above 0 datum level between elevations 0 and $+2500 \mathrm{~m}$ where the simple cinder cones are represented in the southern highland between latitudes $40^{\circ} \mathrm{S}$ and $50^{\circ} \mathrm{S}$ (Figures 6 \& 7). Those which occur at or near the northern ice-cape pole (at latitude $70^{\circ}-75^{\circ} \mathrm{N}$ ) are marked by extensive sand-sized barchans and barchanoid dunes made up of volcanoclastic material which accompanied the eruption of cones (Figure 2a and 2e-2f; Figure 4a). Frozen cinder cones are found at the northern ice-cape (Figure 4e). No criteria for eruption of lava flow through the flanks of the simple cinder cones are recorded except in one cinder cone in the highland hemisphere (series 4). However, steam explosion (water vapor and hematite) may took place after complete cessation of volcanic activity through the peripheral vent of some cinder cones. This is indicated by the presence of streaks of fine dust formed by water vapor around the sides of the summit of simple cinder cones which localized near the northern ice-cap (Figure 2e and 2f; Figure 4a-4b and 4f-4g).

The simple cinder cones are the smallest mountain volcanoes on Mars. The diameter of the summit ranges between $2.35 \mathrm{~km}$ and $17.3 \mathrm{~km}$ with most values lying between $3.5 \mathrm{~km}$ and $14.5 \mathrm{~km}$ and an average value of 7.62 $\mathrm{km}$. The width of the cone (basal diameter) varies in the different studied series from $12.2 \mathrm{~km}$ to $88.6 \mathrm{~km}$ with most values lying between $18.2 \mathrm{~km}$ and $51.0 \mathrm{~km}$ and an average value of $31.18 \mathrm{~km}$. The height of the simple cinder cones varies considerably above ground surface level from $57 \mathrm{~m}$ to $583 \mathrm{~m}$ with most values lying between $80 \mathrm{~m}$ and $317 \mathrm{~m}$ and an average value of $167.0 \mathrm{~m}$ (Figures $8 \& 9$ ). The depth of the summit of the majority of cones is almost higher than the ground surface level and normally less than the height of cone. However, there are several simple cinder cones particularly those which occur in the southern highlands (series 2, 4, 8 and 11) beside some cones of relatively greater width in the northern lowlands (series 14, 15, 17, 19, 20, 22, $24,28,29$ and 30 ) have its summit bottom slightly lower than the ground surface level by $50-370 \mathrm{~m}$. The average depth of summit below ground surface in total studied simple cinder cones is $65 \mathrm{~m}$. The maximum slope of simple cinder cones 


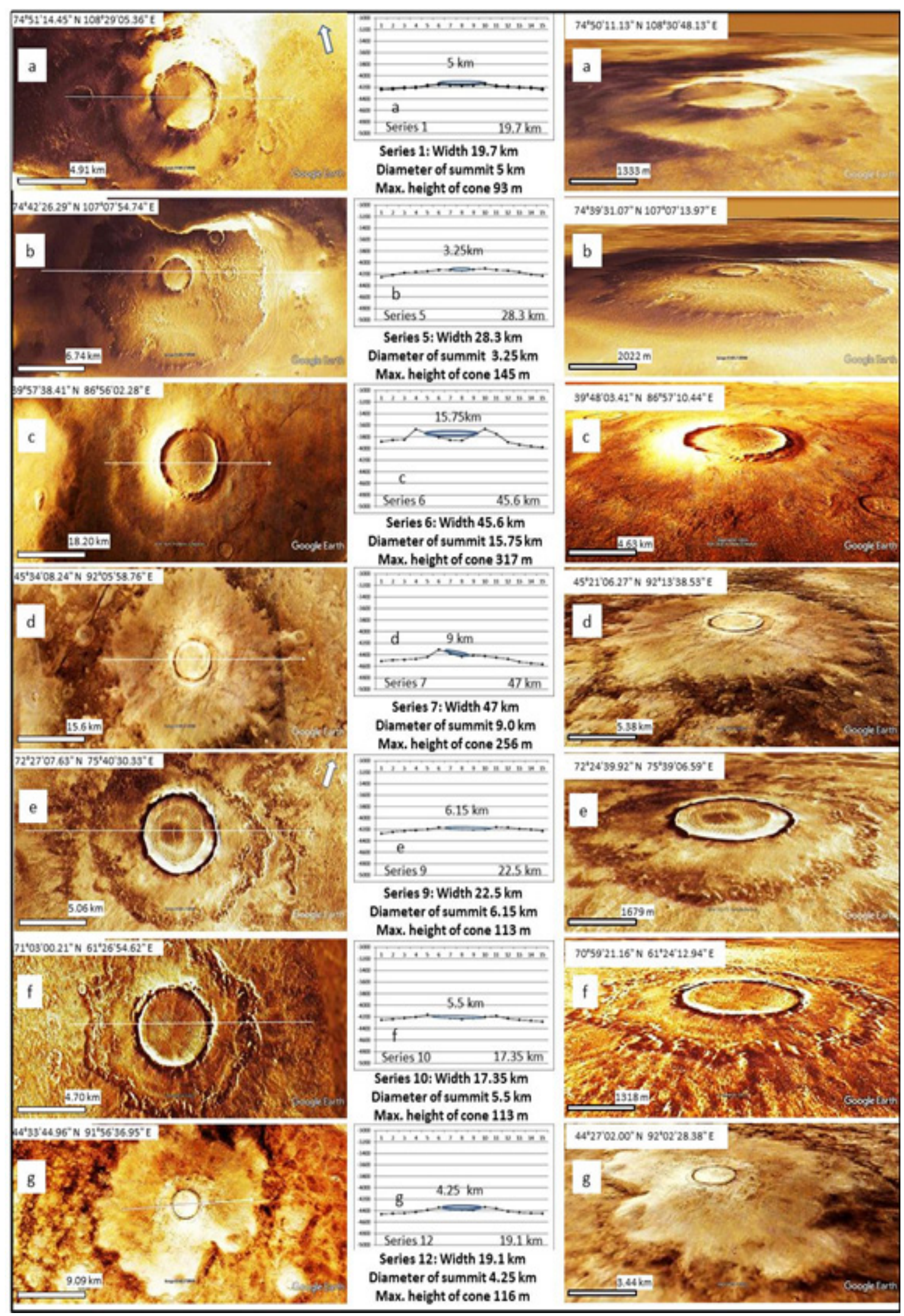

Figure 2: Top view, side view, three dimensional view and morphologic features of Simple Cinder Cones (SCC) in the northern hemisphere below 0 datum (a-g) of Mars.

Citation: Khaled Ak Ouda* and Nadia Af Sharara . Smaller Mountain Volcanoes on Mars: Cinder Cones.

Op Acc J Bio Sci \& Res 5(5)-2020. 


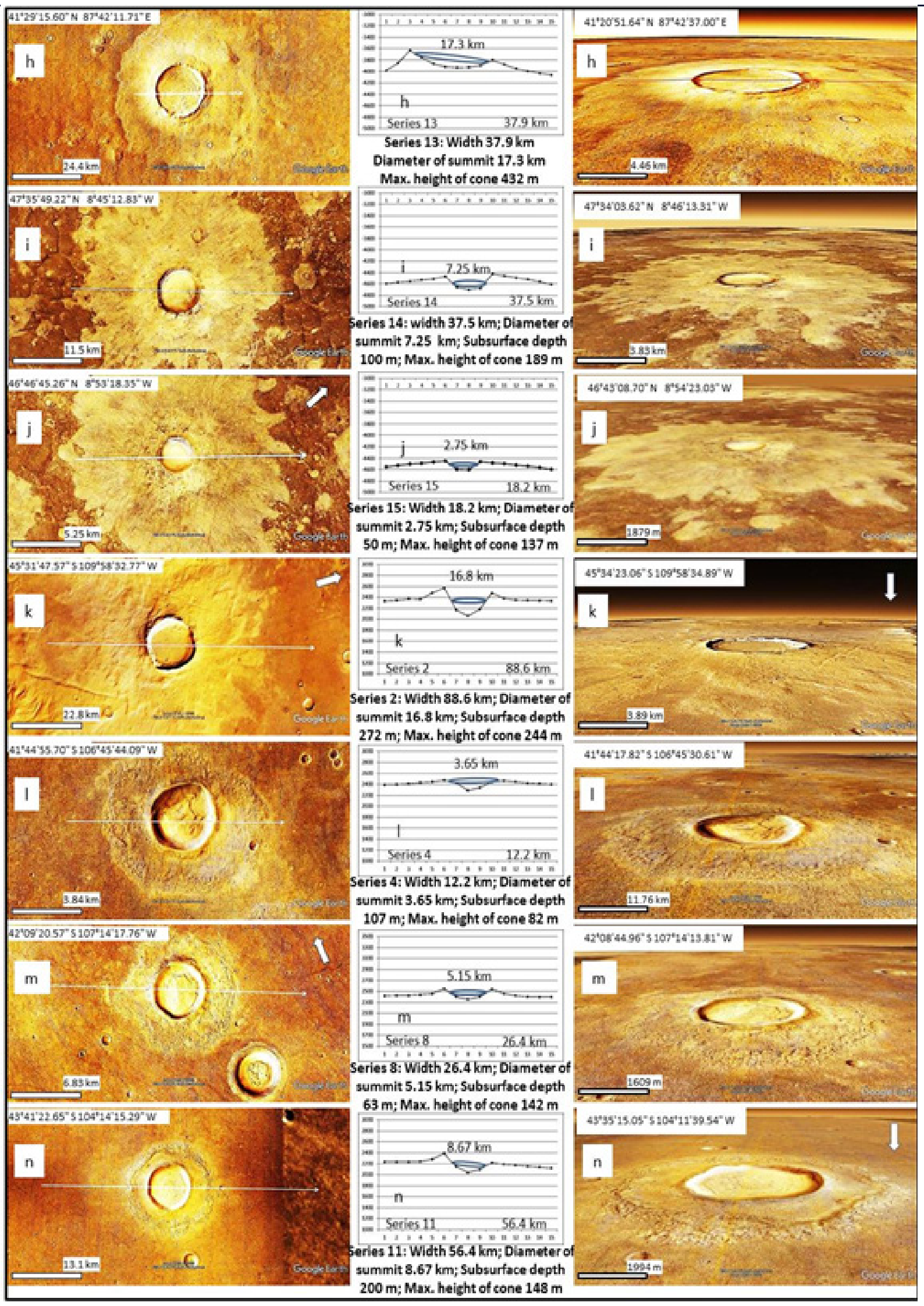

Figure 3: continuation of Figure 2: Top view, side view, three-dimensional view and morphologic features of Simple Cinder Cones (SCC) in the northern hemisphere below 0 datum $(h-j)$ and the southern hemisphere above 0 datum $(k-n)$ of Mars.

Citation: Khaled Ak Ouda* and Nadia Af Sharara . Smaller Mountain Volcanoes on Mars: Cinder Cones. Op Acc J Bio Sci \& Res 5(5)-2020. 


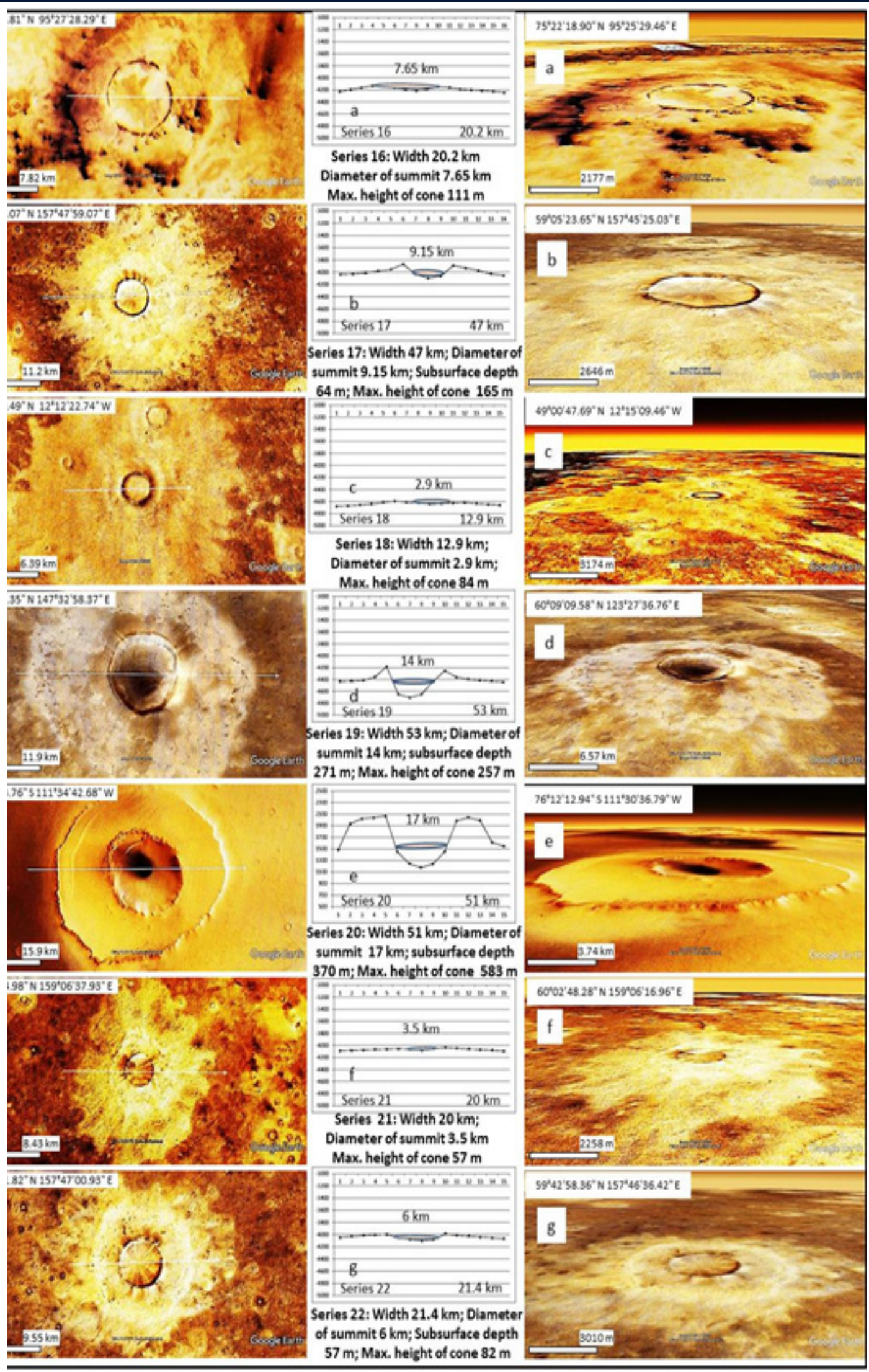

Figure 4: Top view, side view, three-dimensional view and morphologic features of Simple Cinder Cones (SCC) in the northern hemisphere below 0 datum ( $a-d$ and $f$-g) and the southern hemisphere above 0 datum (e) of Mars.

Citation: Khaled Ak Ouda* and Nadia Af Sharara. Smaller Mountain Volcanoes on Mars: Cinder Cones.

Op Acc J Bio Sci \& Res 5(5)-2020. 

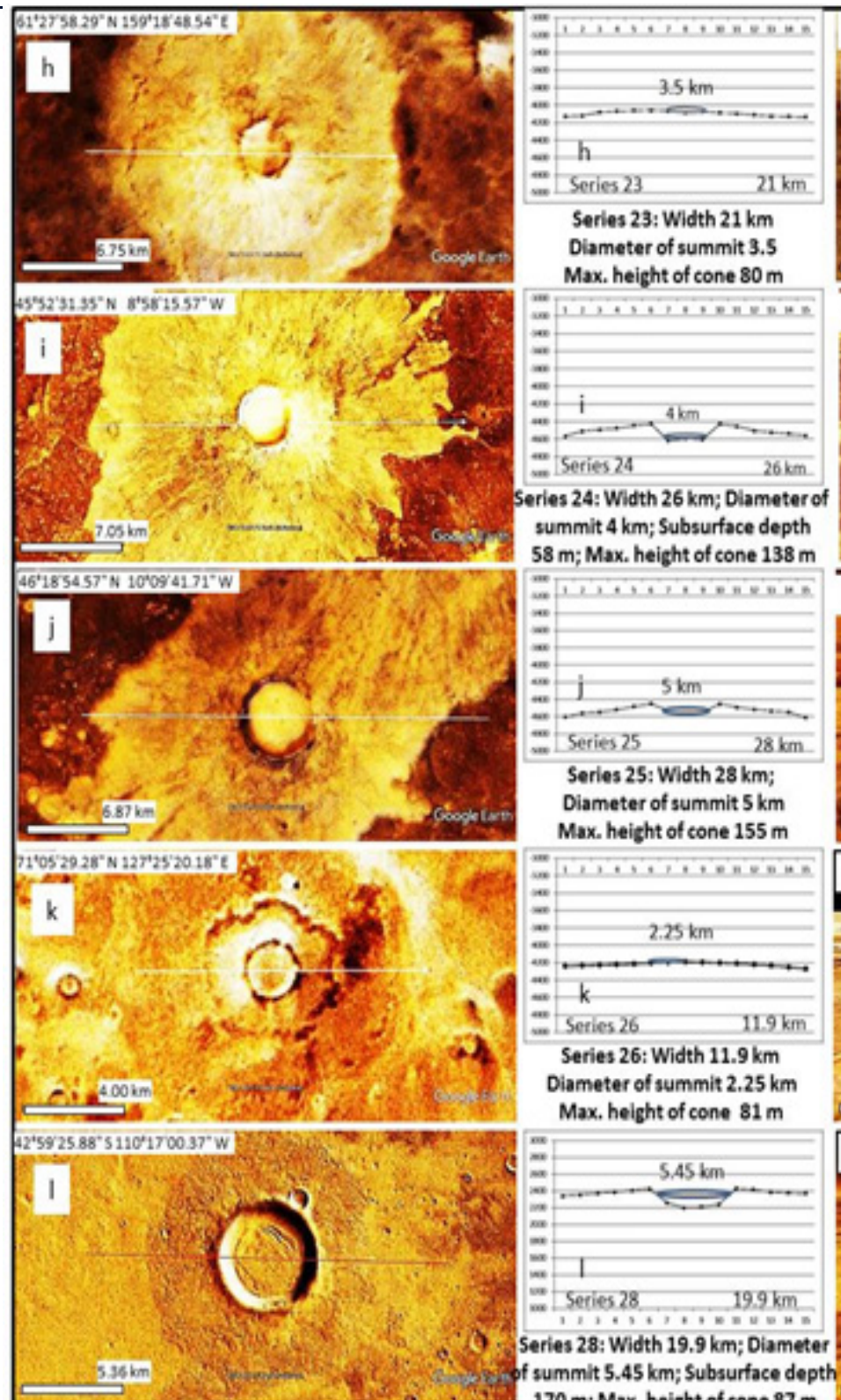
Max. height of cone $80 \mathrm{~m}$

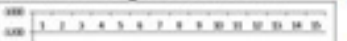

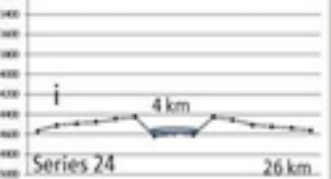

eries 24 : Width $26 \mathrm{~km}$; Diameter of summit $4 \mathrm{~km}$; Subsurface depth $58 \mathrm{~m}$; Max. height of cone $138 \mathrm{~m}$
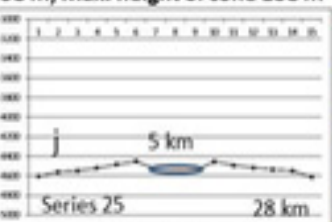

Series 25: Width $28 \mathrm{~km}$;

Diameter of summit $5 \mathrm{~km}$

Max, height of cone $155 \mathrm{~m}$

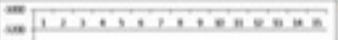

$61^{1} 251155^{\circ} \mathrm{N} 159^{\circ} 1 \gamma^{17} 17.86^{\circ} \mathrm{E}$
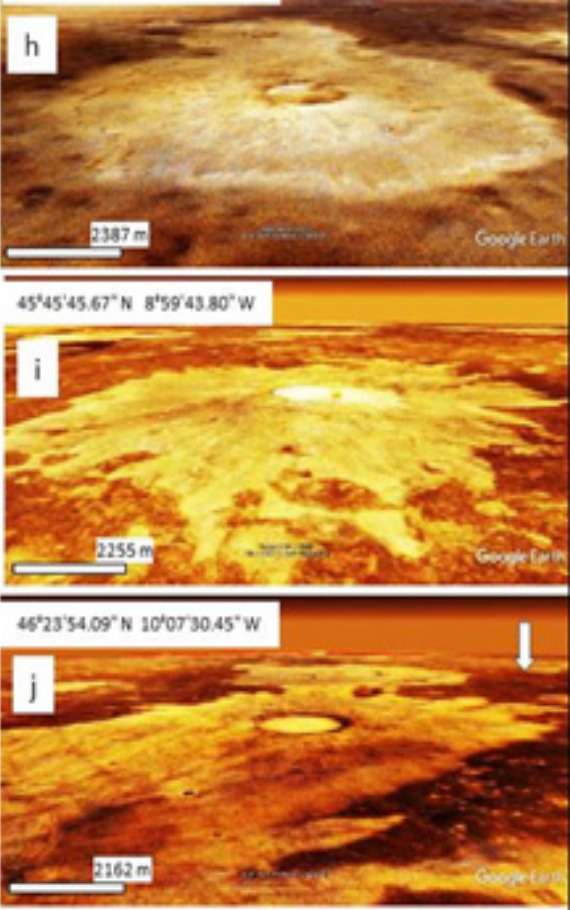

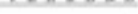

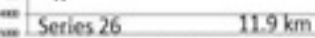

Series 26: Width $11.9 \mathrm{~km}$

Diameter of summit $2.25 \mathrm{~km}$

Max, height of cone $81 \mathrm{~m}$
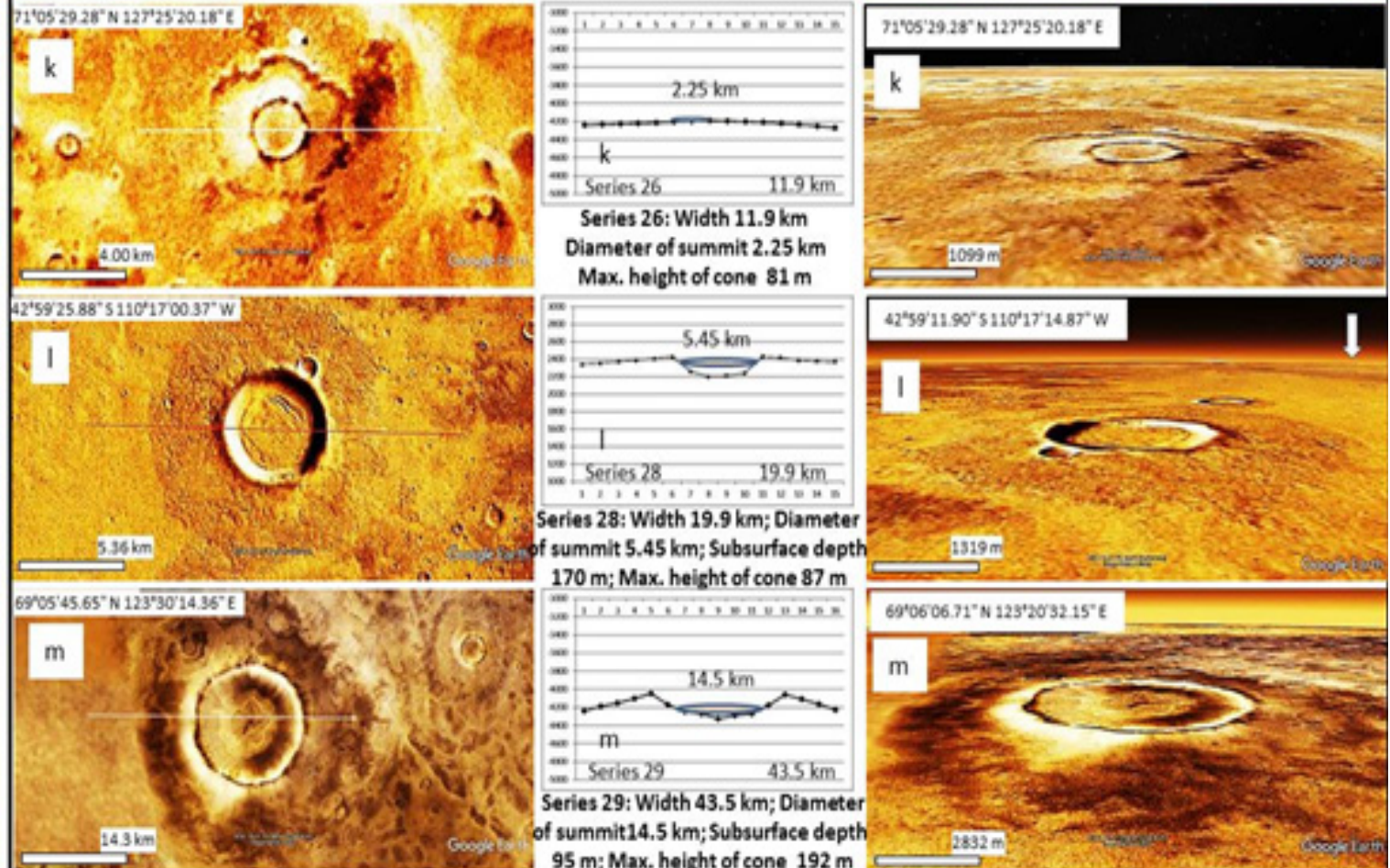

Series 28: Width $19.9 \mathrm{~km}$; Diamete

f summit $5.45 \mathrm{~km}$; Subsurface depth $170 \mathrm{~m}$; Max. height of cone $87 \mathrm{~m}$

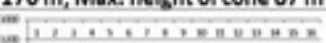
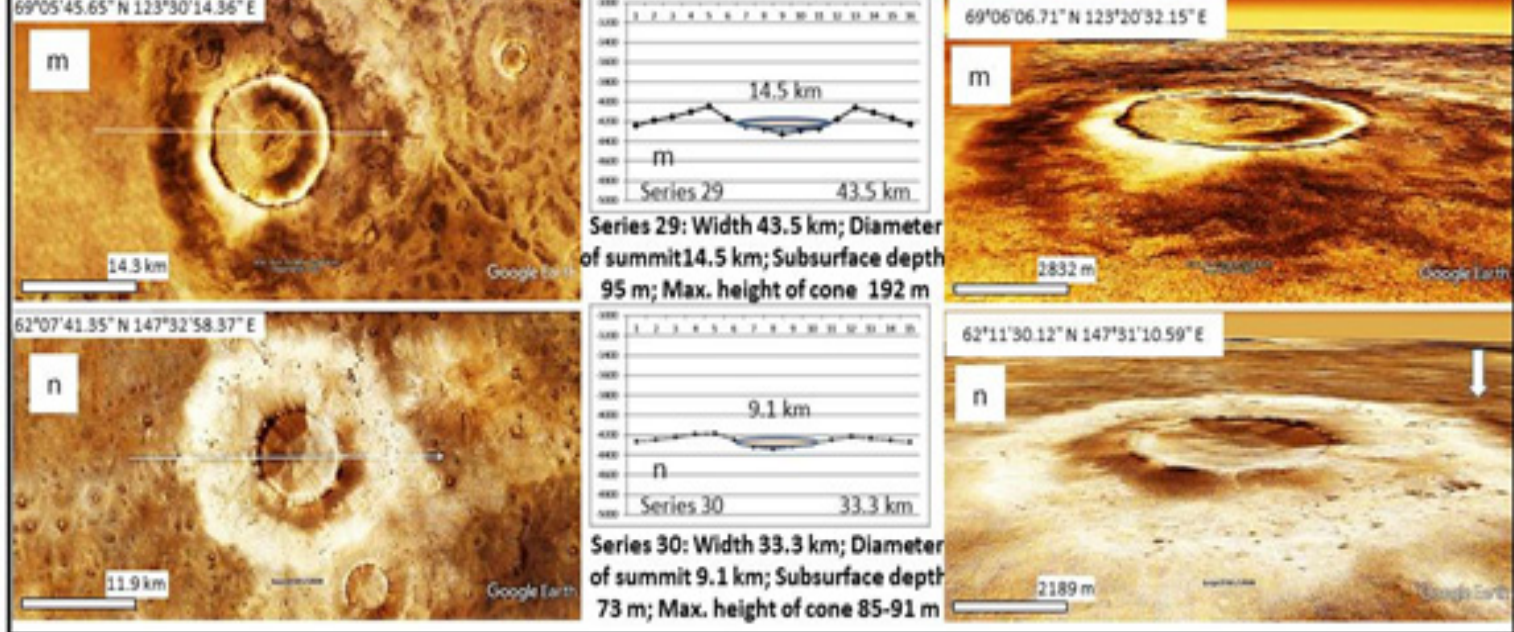

Figure 5: continuation of Figure 4: Top view, side view, three-dimensional view and morphologic features of Simple Cinder Cones (SCC) in the northern hemisphere below 0 datum ( $h-k$ and $m-n)$, and in the southern hemisphere above 0 datum of Mars (I).

Citation: Khaled Ak Ouda* and Nadia Af Sharara. Smaller Mountain Volcanoes on Mars: Cinder Cones.

Op Acc J Bio Sci \& Res 5(5)-2020. 
Topographic data of Simple Cinder Cone (SCC)

\begin{tabular}{|c|c|c|c|c|c|c|c|c|c|c|c|c|c|c|c|}
\hline $\begin{array}{c}\text { Series of } \\
\text { Simple } \\
\text { Cinder Cond }\end{array}$ & 1 & 2 & 3 & 4 & 5 & 6 & 7 & 8 & 9 & 10 & 11 & 12 & 13 & 14 & 15 \\
\hline \multirow{15}{*}{ 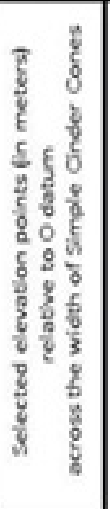 } & -4230 & 2332 & -4120 & 2393 & -4250 & -3850 & -4508 & 2421 & -4270 & .4252 & 2242 & -4460 & -3984 & $\$ 600$ & -4554 \\
\hline & .4223 & 2345 & -4111 & 2399 & .4215 & .3852 & .4492 & 2426 & -4242 & -4237 & 2242 & .4450 & .3850 & .4572 & .4529 \\
\hline & -4210 & 2372 & -4101 & 2412 & -4175 & .3848 & -4483 & 2429 & -4225 & -4220 & 2241 & -4440 & -3633 & .4552 & -4506 \\
\hline & -4200 & 2365 & -4093 & 2430 & -4165 & -3668 & -4473 & 2441 & -4212 & -4201 & 2244 & -4423 & -3758 & -4531 & 4490 \\
\hline & -4172 & 2479 & -4079 & 2445 & .4154 & .3748 & .4438 & 2462 & .4196 & 4167 & 2287 & -4388 & .3862 & 4510 & -4470 \\
\hline & -4143 & 2576 & -4051 & 2475 & .4125 & -3803 & -4310 & 2548 & -4166 & .4186 & 2390 & -4344 & -3915 & 4468 & .4452 \\
\hline & .4158 & 2173 & -4050 & 2431 & 4130 & .3852 & -4379 & 2403 & -4175 & 4222 & 2148 & -4367 & -3930 & 4662 & .4597 \\
\hline & -4166 & 2063 & -4060 & 2290 & -4141 & -3861 & -4433 & 2358 & -4187 & -4238 & 2042 & -4381 & -3925 & 4700 & -4604 \\
\hline & .4159 & 2187 & -4050 & 2340 & 4120 & .3766 & -4410 & 2405 & 4203 & 4221 & 2094 & -4389 & -3889 & 4676 & -4461 \\
\hline & -4137 & 2475 & -4043 & 2441 & -4105 & -3663 & -4423 & 2542 & -4194 & -4201 & 2220 & -4336 & -3801 & 4421 & -4487 \\
\hline & -417 & 2381 & -4057 & 2469 & -4129 & -3748 & -4452 & 2460 & 4157 & -4185 & 2191 & -4365 & -3874 & 4458 & .4500 \\
\hline & -4191 & 2351 & -4078 & 2446 & 4138 & .3889 & -4471 & 2425 & -4167 & .4229 & 2175 & -4410 & -3950 & 4490 & .4525 \\
\hline & -4200 & 2346 & -4099 & 2421 & -4165 & -3933 & -4525 & 2405 & -4188 & -4253 & 2155 & -4433 & -3994 & -4520 & -4544 \\
\hline & -4210 & 2342 & -4115 & 2411 & .4205 & $=3962$ & -4545 & 2401 & -4201 & .4266 & 2137 & -4444 & -4033 & .4562 & .4565 \\
\hline & -4230 & 2335 & -4123 & 2397 & -4232 & -3980 & -4566 & 2400 & -4225 & -4280 & 2117 & -4448 & -4065 & 4610 & .4598 \\
\hline
\end{tabular}

\section{Representation of Data}

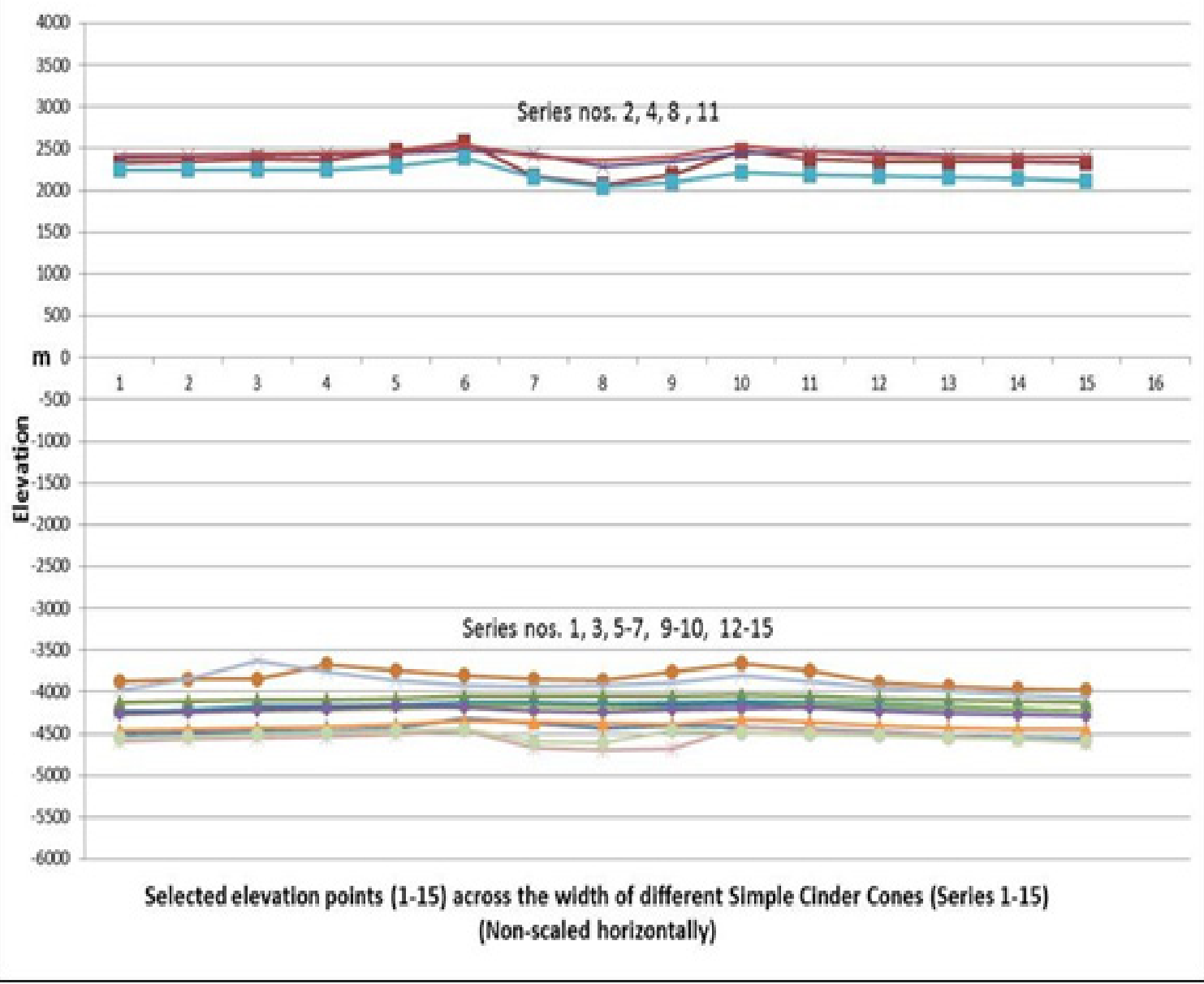

Figure 6: Topography and topographic location of different Simple Cinder Cones (SCC) with respect to 0 datum on Mars. The measurements of elevation (from 1 to 15) are more or less symmetrically spaced across the width of each simple cinder cone, but the width of cones is not constant throughout. To know details of diameter of summit, width of cone, subsurface depth of the summit and height of cone of each series of SCC see Figure 8.

Citation: Khaled Ak Ouda* and Nadia Af Sharara. Smaller Mountain Volcanoes on Mars: Cinder Cones.

Op Acc J Bio Sci \& Res 5(5)-2020. 


\section{Topographic data of Simple Cinder Cone (SCC)}

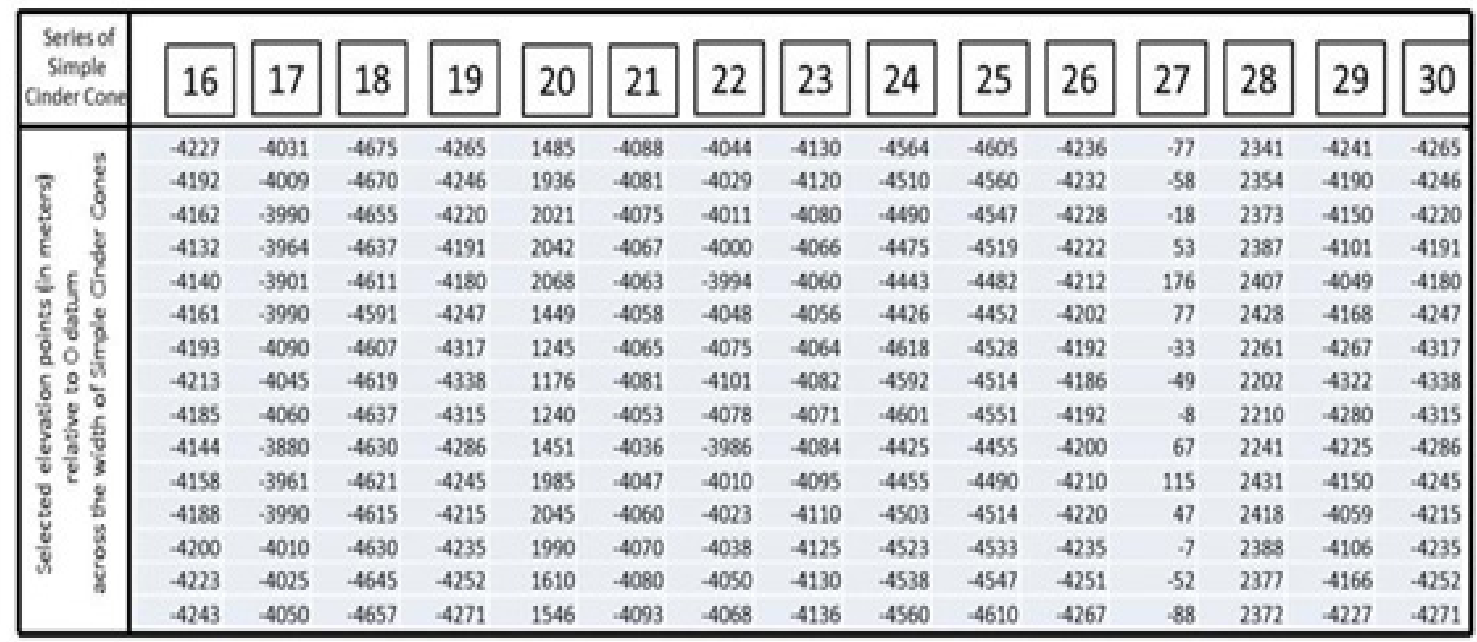

\section{Representation of Data}

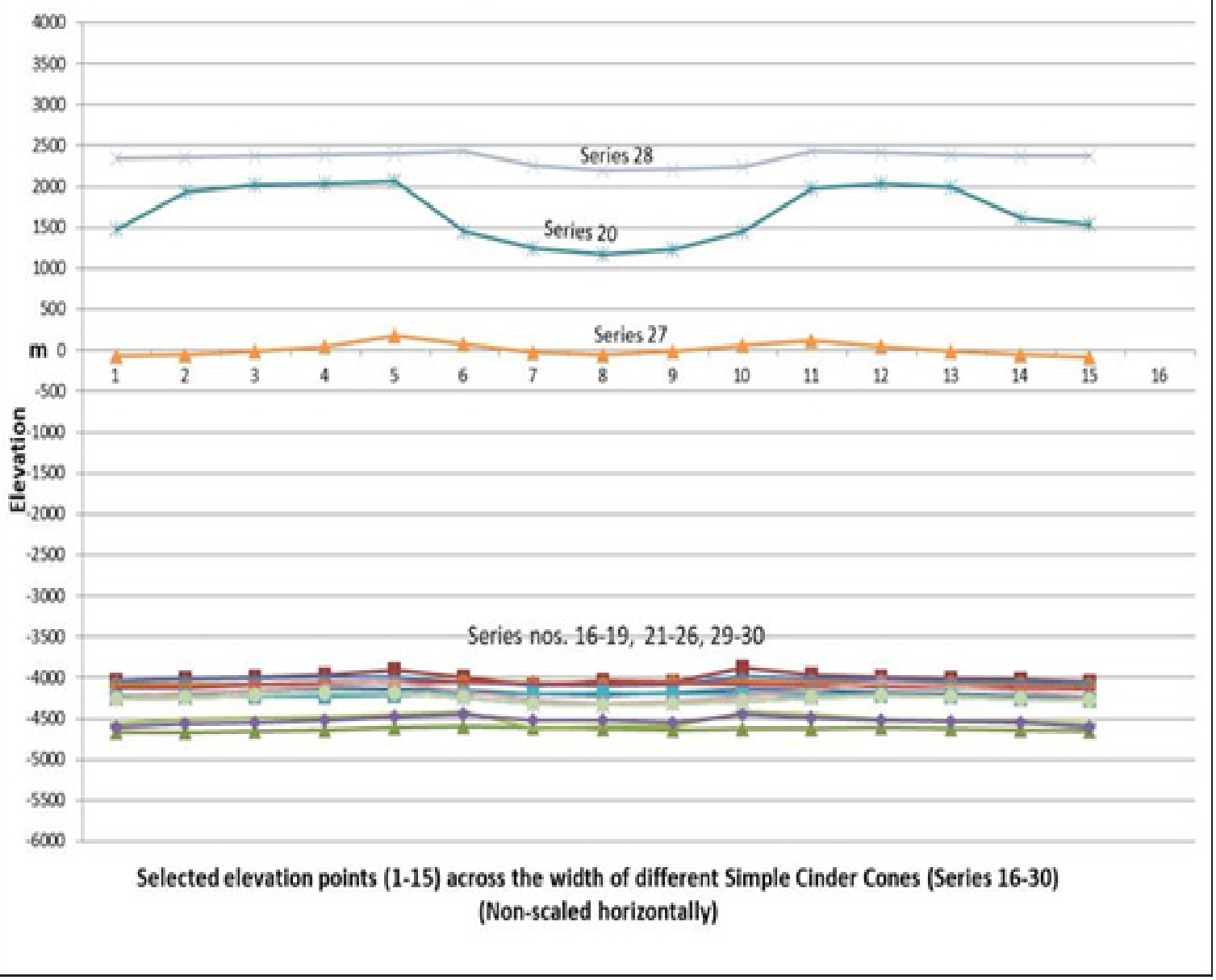

Figure 7: continuation of Topography and topographic location of different Simple Cinder Cones (SCC, series 16-30) with respect to 0 datum on Mars. The measurements of elevation (from 1 to 15) are more or less symmetrically spaced across the width of each simple cinder cone, but the width of cones is not constant throughout. To know details of diameter of summit, width of cone, subsurface depth of the summit and height of cone of each series of SCC see Figure 8.

Citation: Khaled Ak Ouda* and Nadia Af Sharara. Smaller Mountain Volcanoes on Mars: Cinder Cones.

Op Acc J Bio Sci \& Res 5(5)-2020. 


\begin{tabular}{|c|c|c|c|c|c|c|}
\hline \multicolumn{7}{|c|}{ Morphologic data of Simple Cinder Cones (SCC) } \\
\hline : & ๘荦 & 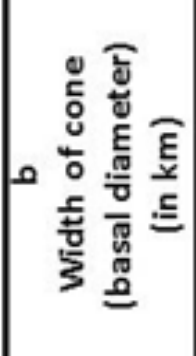 & 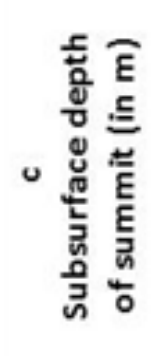 & 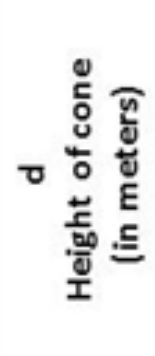 & 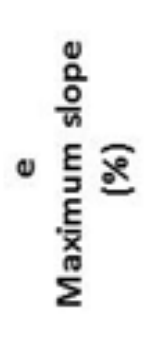 & 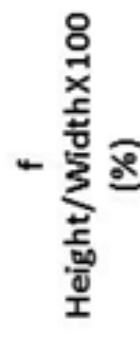 \\
\hline series 1 & 5 & 19.7 & 0 & 93 & 6.85 & 0.47 \\
\hline series 2 & 16.8 & 88.6 & 272 & 144 & 25.25 & 0.16 \\
\hline series 3 & 2.35 & 15.9 & 0 & 80 & 5.1 & 0.5 \\
\hline series 4 & 3.65 & 12.2 & 107 & 82 & 16.4 & 0.67 \\
\hline series $\mathbf{5}$ & 3.25 & 28.3 & 0 & 145 & 4.1 & 0.51 \\
\hline series 6 & 15.75 & 45.6 & 0 & 317 & 11.7 & 0.7 \\
\hline series 7 & 9 & 47 & 0 & 256 & 7.15 & 0.54 \\
\hline series 8 & 5.15 & 26.4 & 63 & 142 & 32.5 & 0.54 \\
\hline series 9 & 6.15 & 22.5 & 0 & 113 & 5.8 & 0.5 \\
\hline series 10 & 5.5 & 17.35 & 0 & 113 & 10 & 0.65 \\
\hline series 11 & 8.67 & 56.4 & 200 & 148 & 40.7 & 0.26 \\
\hline series 12 & 4.25 & 19.1 & 0 & 116 & 9.65 & 0.6 \\
\hline series13 & 17.3 & 37.9 & 0 & 432 & 17.65 & 1.14 \\
\hline series 14 & 7.25 & 37.5 & 100 & 189 & 23.7 & 0.5 \\
\hline series 15 & 2.75 & 18.2 & 50 & 137 & 19.1 & 0.75 \\
\hline series 16 & 7.65 & 20.2 & 0 & 111 & 5.25 & 0.55 \\
\hline series 17 & 9.15 & 47 & 64 & 165 & 15 & 0.35 \\
\hline series 18 & 2.9 & 12.9 & 0 & 84 & 4.55 & 0.65 \\
\hline series 19 & 14 & 53 & 271 & 257 & 22.7 & 0.48 \\
\hline series 20 & 17 & 51 & 370 & 583 & 30.3 & 1.14 \\
\hline series 21 & 3.5 & 20 & 0 & 57 & 3.65 & 0.29 \\
\hline series 22 & 6 & 21.4 & 57 & 82 & 11.1 & 0.38 \\
\hline series 23 & 3.5 & 21 & 0 & 80 & 4.15 & 0.38 \\
\hline series 24 & 4 & 26 & 58 & 138 & 29.3 & 0.53 \\
\hline series 25 & 5 & 28 & 0 & 155 & 12.8 & 0.55 \\
\hline series 26 & 2.25 & 11.9 & 0 & 81 & 2.2 & 0.68 \\
\hline series 27 & 11.75 & 33.6 & 0 & 253 & 13.8 & 0.75 \\
\hline Series 28 & 5.45 & 19.9 & 170 & 87 & 23 & 0.44 \\
\hline series 29 & 14.5 & 43.5 & 95 & 192 & 11.1 & 0.44 \\
\hline series 30 & 9.1 & 33.3 & 73 & 91 & 12.85 & 0.27 \\
\hline
\end{tabular}

Figure 8: Measured parameters in Simple Cinder Cones; a-diameter of summit ( $\mathrm{km})$; $b$-width of cone (km); c-subsurface depth below ground surface $(m)$; $d$ - height above surroundings (m); e- maximum slope of cone (\%); f-height/width X100 (\%).

Citation: Khaled Ak Ouda* and Nadia Af Sharara. Smaller Mountain Volcanoes on Mars: Cinder Cones. Op Acc J Bio Sci \& Res 5(5)-2020. 
a

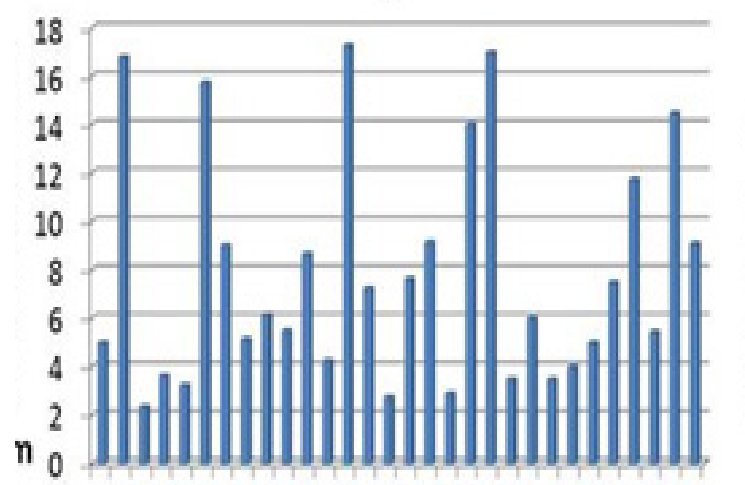

$\begin{array}{lllllll}1 & 3 & 7 & 9 & 1131517192123252729\end{array}$

Number of volcanic series of SCC

C
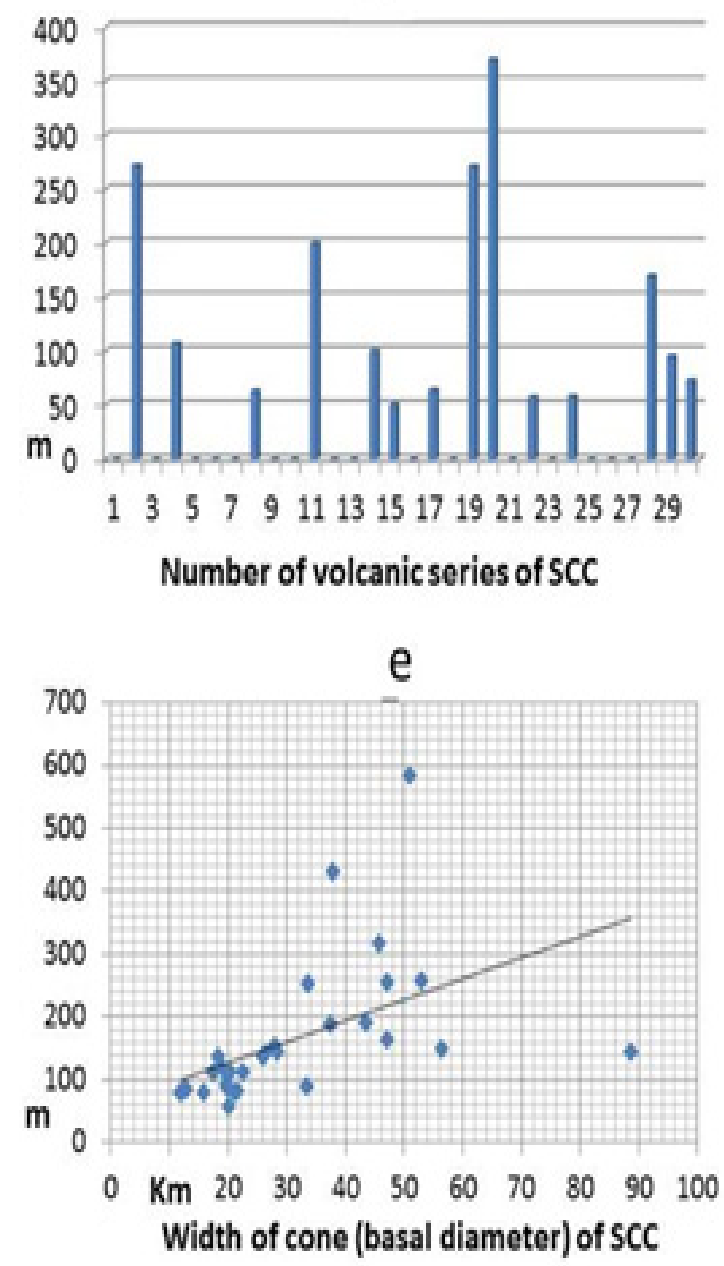

b

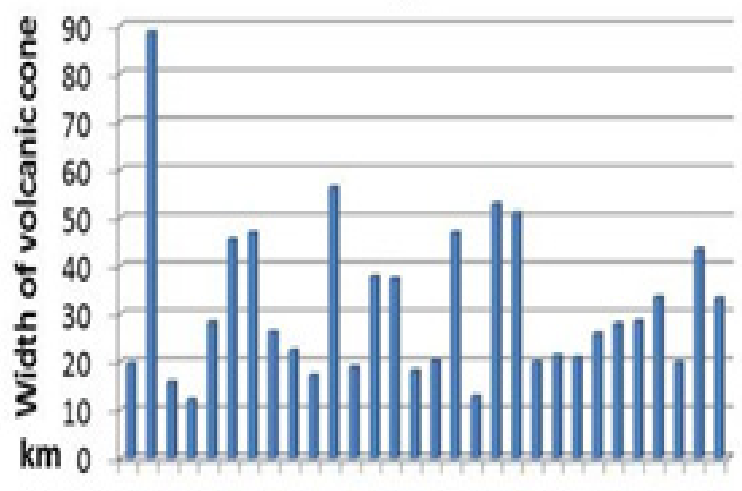

1357911131517192123252729

Number of volcanic series of SCC

d

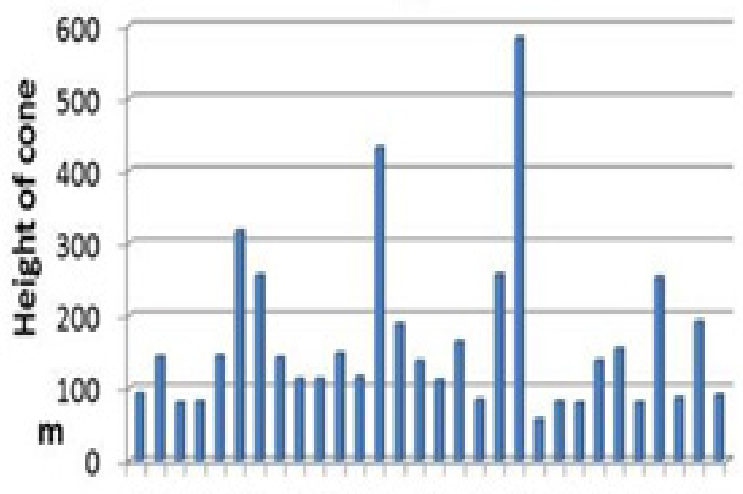

1357911131517192123252729

Number of volcanic series of SCC

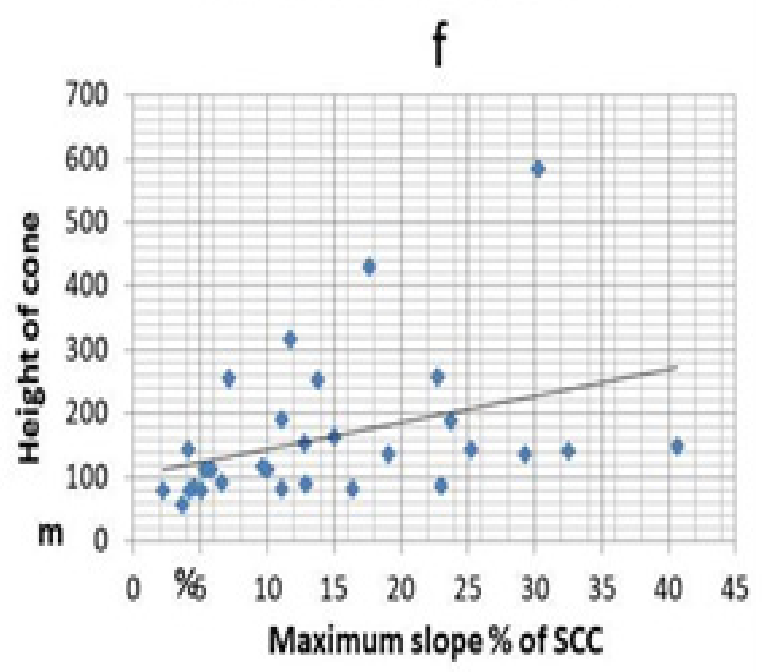

Figure 9: Representation of morphologic features of Simple Cinder Cones (SCC) on Mars: a-Diameter of summit (in km), b-Width of cone (basal diameter, in $\mathrm{km}$ ), c-Subsurface depth of summit below ground surface, (in meters), $d$ - Height of cone above ground surface (in meters), e- Height (m) versus width of cone $(\mathrm{km})$. $f$ - Height of cone $(\mathrm{m})$ versus maximum slope (\%)

Citation: Khaled Ak Ouda* and Nadia Af Sharara. Smaller Mountain Volcanoes on Mars: Cinder Cones. Op Acc J Bio Sci \& Res 5(5)-2020. 


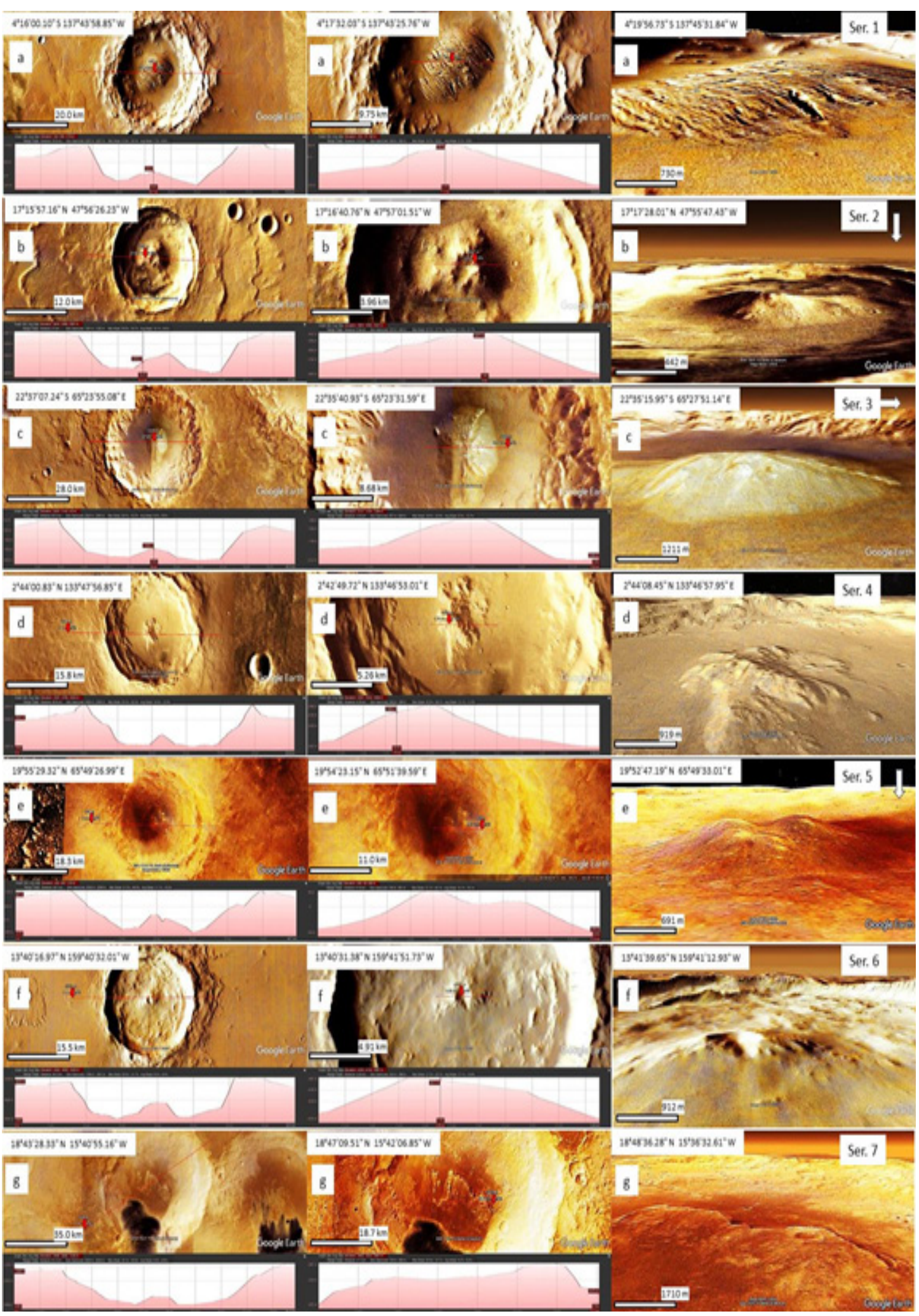

Figure 10: A-G-Electronic profiles and three-dimensional images showing parasitic cinder cones covering the central vent at the bottom floor of large complex collapse calderas as a result of re-filling of the magma chamber below the vent and re-eruption on the bottom floor of pre-existing caldera. The left column is a cross section of the caldera showing a younger phase of eruption of parasitic cinder cones over the central vent at the bottom of the collapsed caldera. The middle column is a cross section of the parasitic cinder cones. The right column is a three dimensional of the parasitic cinder cones. a and c-from the southern hemisphere; $b, d$ and e-g-from the northern hemisphere of Mars.

Citation: Khaled Ak Ouda* and Nadia Af Sharara. Smaller Mountain Volcanoes on Mars: Cinder Cones. Op Acc J Bio Sci \& Res 5(5)-2020. 


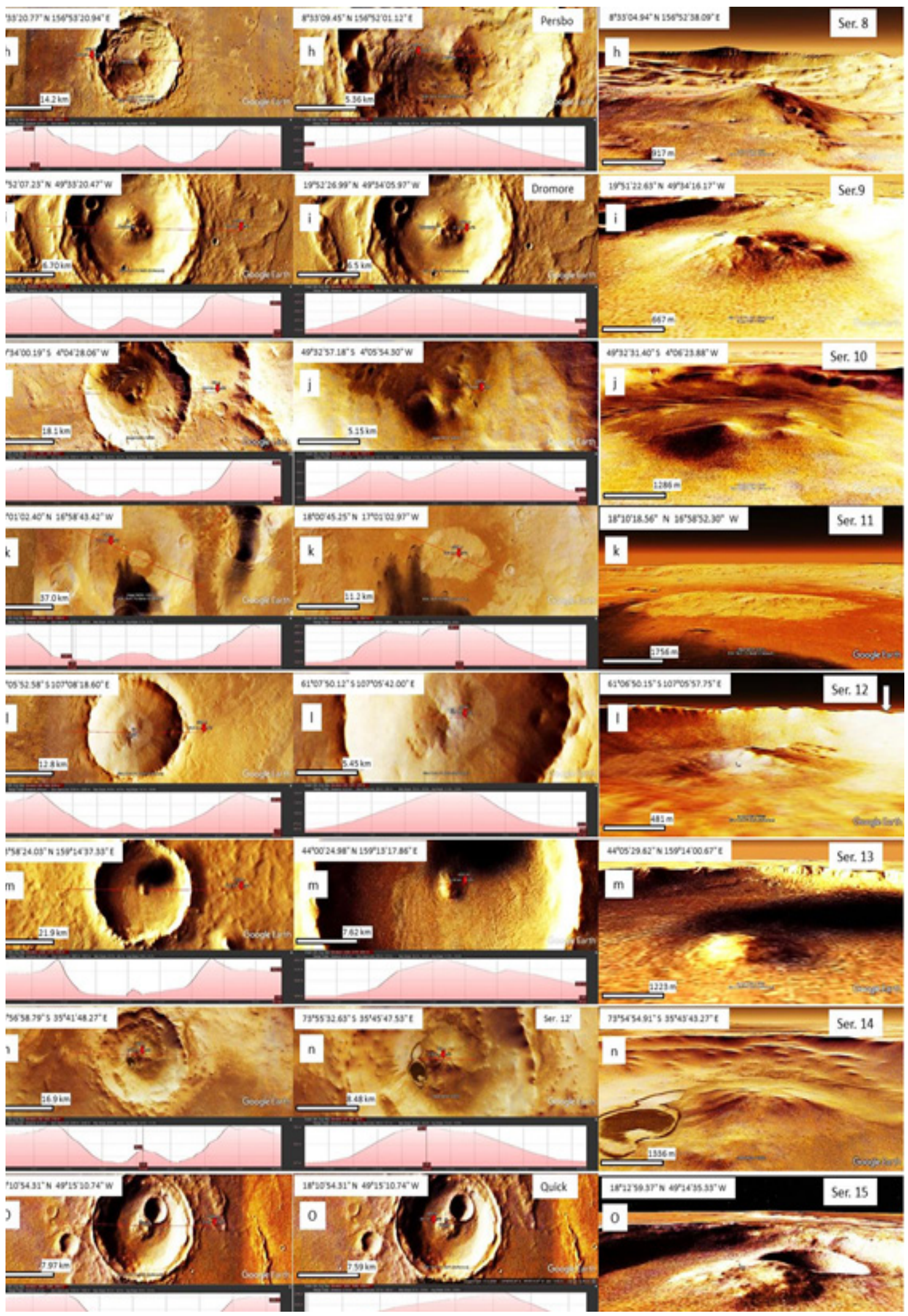

Figure 11: continuation of Figure 10: $h$-o- Electronic profiles and three-dimensional images showing parasitic cinder cones covering the central vent at the bottom floor of large complex collapse calderas. For details see Figure 10 . H-i, $k, m$ and o, from the northern hemisphere; $j$, I and $n$, from the southern hemisphere of Mars

Citation: Khaled Ak Ouda* and Nadia Af Sharara. Smaller Mountain Volcanoes on Mars: Cinder Cones.

Op Acc J Bio Sci \& Res 5(5)-2020. 


\section{Parasitic Cinder cones compared to independent Cinder Cones}

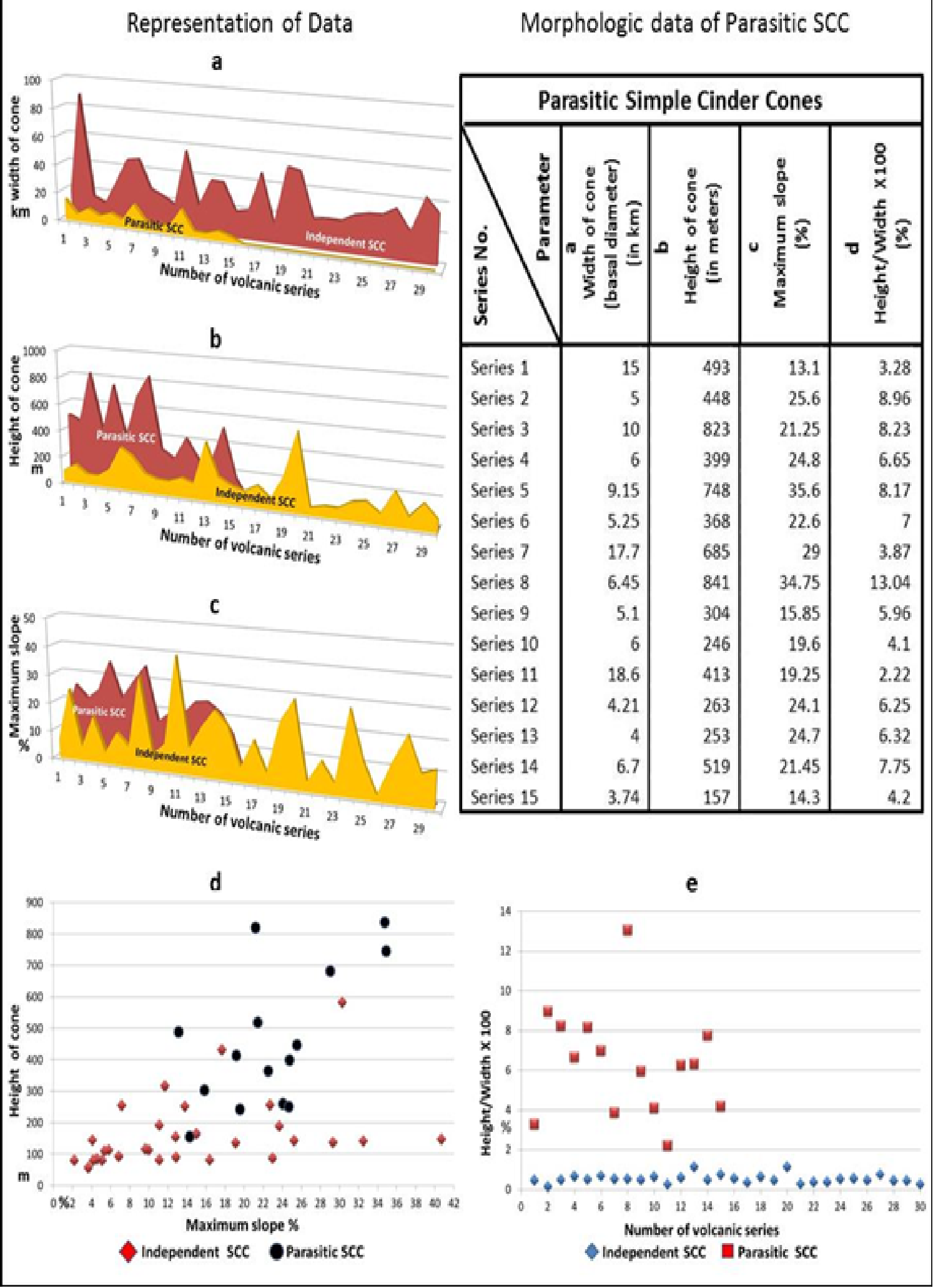

Figure 12: Morphologic data of parasitic cinder cones on Mars and correlation of independent and parasitic simple cinder cones; awidth of cone (basal diameter, $\mathrm{km}$ ), b-height of cone (m); c-maximum slope of cone (\%); d-height/width X 100 (\%); e- height of cone (m) versus maximum slope (\%). Data of simple cinder cones are given in Figure 8.

Citation: Khaled Ak Ouda* and Nadia Af Sharara. Smaller Mountain Volcanoes on Mars: Cinder Cones. Op Acc J Bio Sci \& Res 5(5)-2020. 


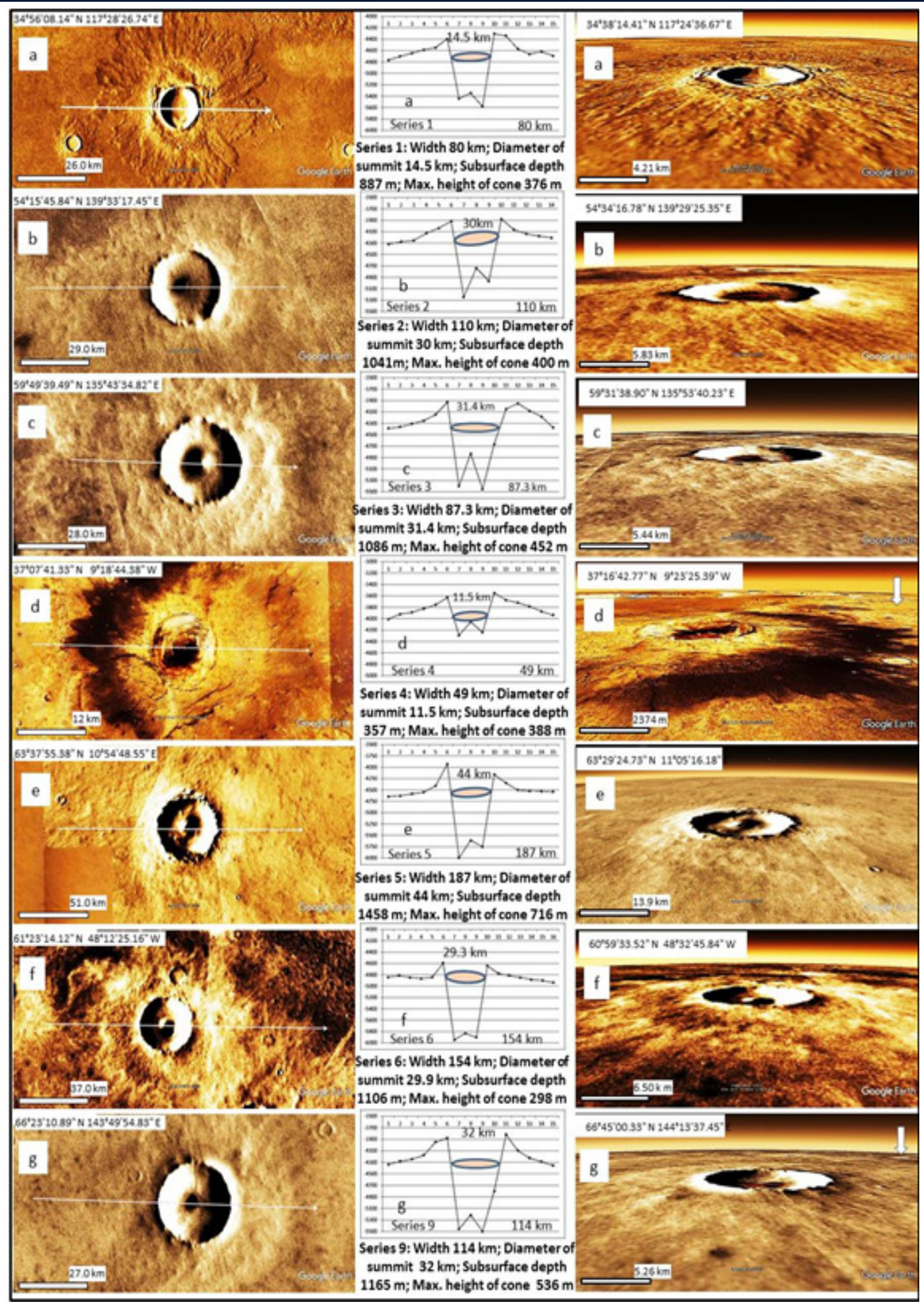

Figure 13: Top view, side view, three-dimensional view and morphologic features of Modified Cinder Cones (MCC) in the northern hemisphere below 0 datum (a-g) of Mars.

Citation: Khaled Ak Ouda* and Nadia Af Sharara . Smaller Mountain Volcanoes on Mars: Cinder Cones. Op Acc J Bio Sci \& Res 5(5)-2020. 


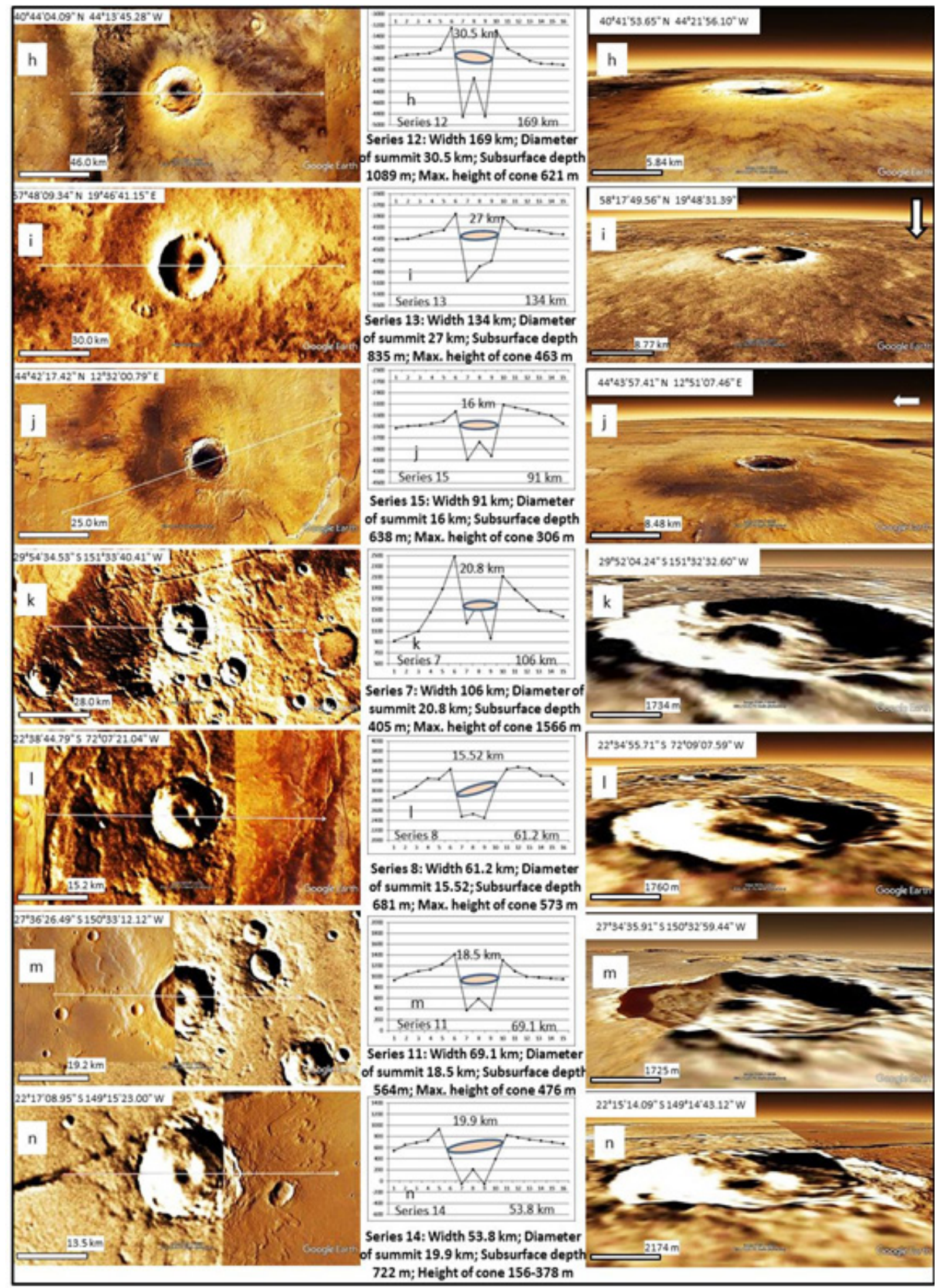

Figure 14: continuation of Figure 13: Top view, side view, three-dimensional view and morphologic features of Modified Cinder Cones (MCC) in the northern hemisphere below 0 datum ( $h-j)$ and the southern hemisphere above 0 datum ( $k-n)$ of Mars.

Citation: Khaled Ak Ouda* and Nadia Af Sharara. Smaller Mountain Volcanoes on Mars: Cinder Cones. Op Acc J Bio Sci \& Res 5(5)-2020. 


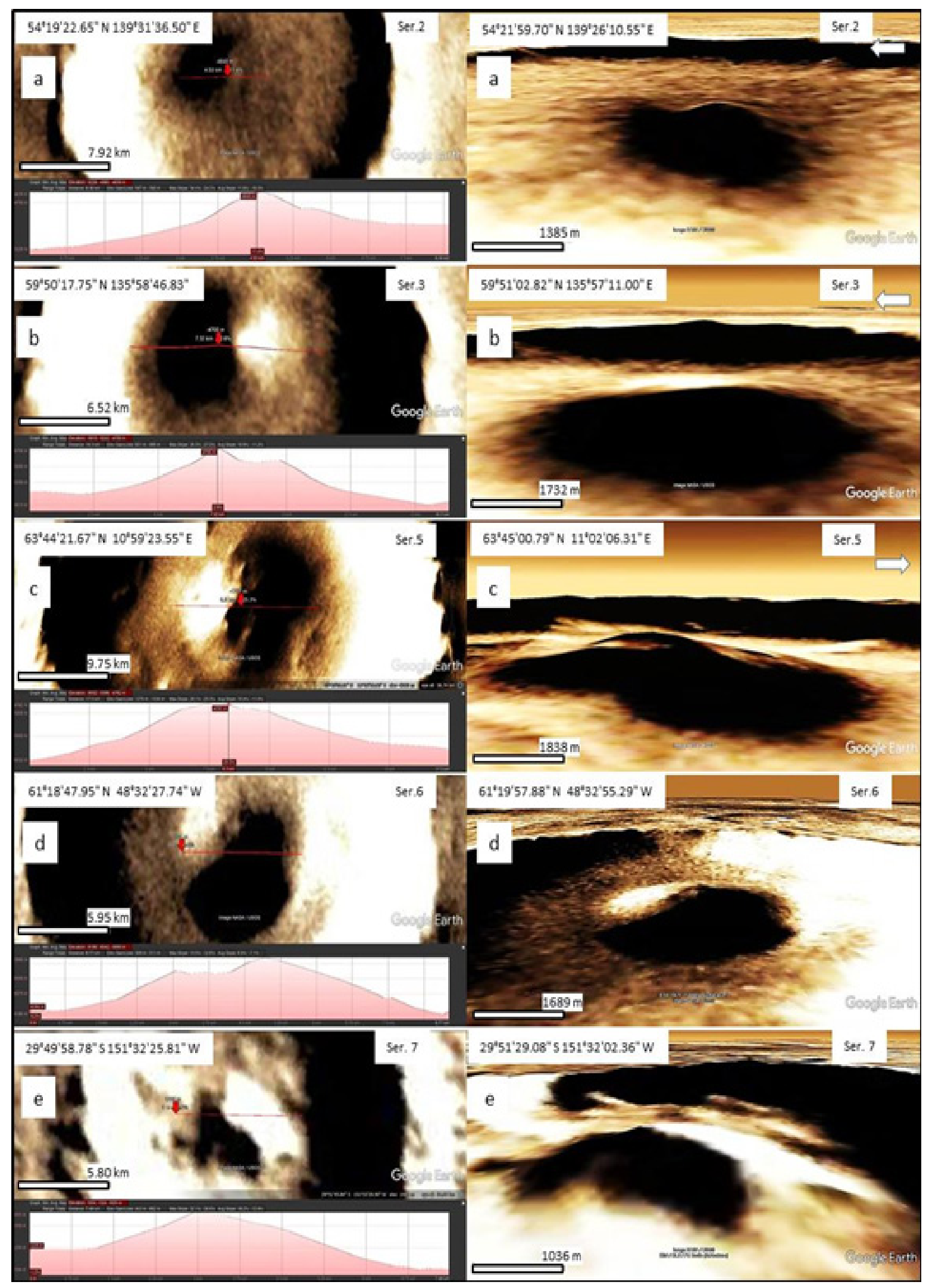

Figure 15: Electronic profiles and three-dimensional images of the volcanic domes which re-erupt from the central vent at the bottom floor of the summit of the Modified Cinder Cones (MCC) after re-filling of the magma chamber in the northern (a-d) and southern (e) hemispheres of Mars.

Citation: Khaled Ak Ouda* and Nadia Af Sharara. Smaller Mountain Volcanoes on Mars: Cinder Cones. Op Acc J Bio Sci \& Res 5(5)-2020. 


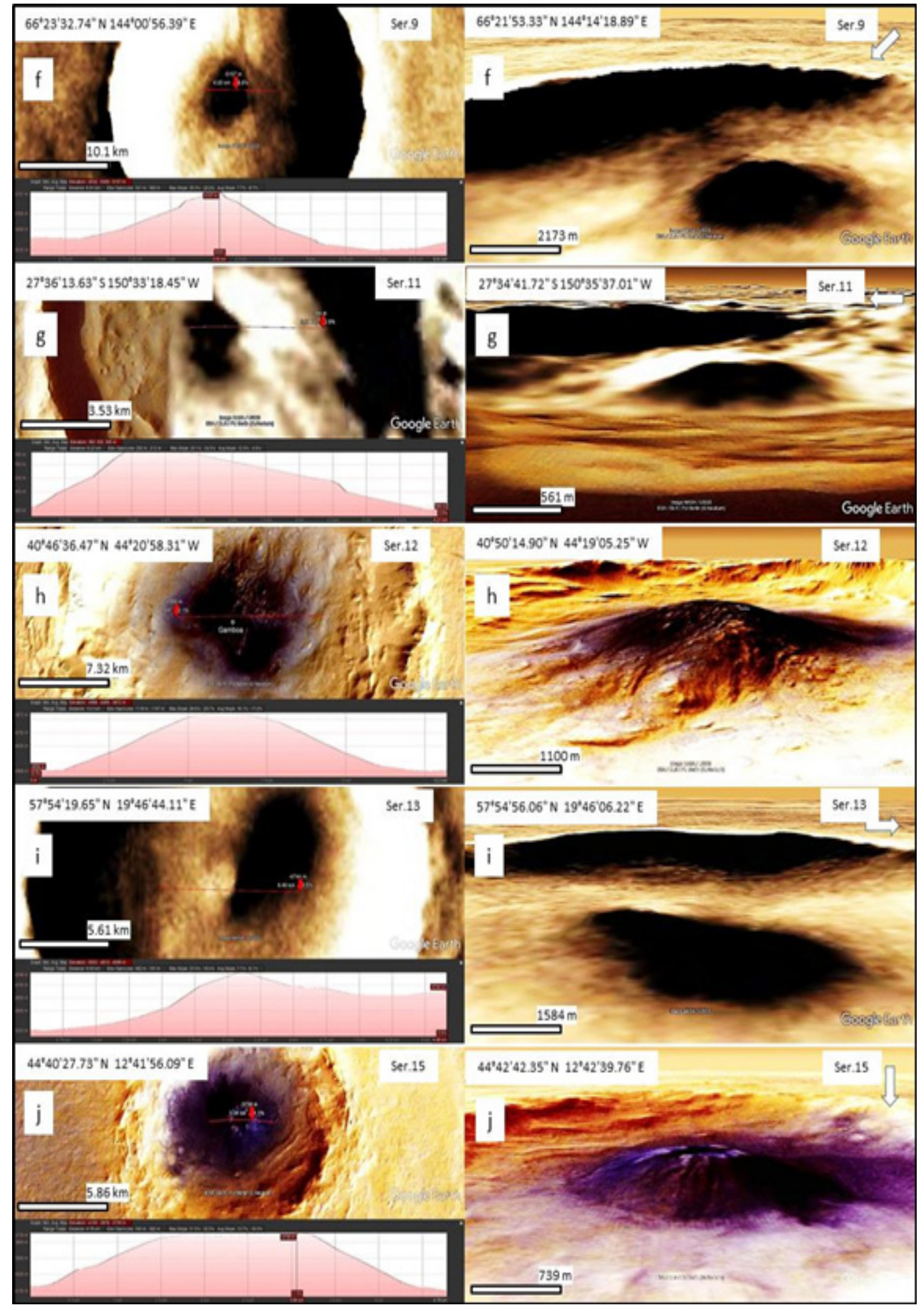

Figure 16: continuation of Figure 15: Electronic profiles and three-dimensional images of the volcanic domes which re-erupt from the central vent at the bottom floor of the summit of the modified cinder cones (MCC) after re-filling of the magma chamber in the northern ( $f$ and $h-j$ ) and southern $(g)$ hemispheres of Mars.

Citation: Khaled Ak Ouda* and Nadia Af Sharara. Smaller Mountain Volcanoes on Mars: Cinder Cones. Op Acc J Bio Sci \& Res 5(5)-2020. 
Topographic data of Modified Cinder Cone (MCC)

\begin{tabular}{|c|c|c|c|c|c|c|c|c|c|c|c|c|c|c|c|}
\hline $\begin{array}{l}\text { Serles of } \\
\text { Modiffed } \\
\text { Cinder Cone }\end{array}$ & 1 & 2 & 3 & 4 & 5 & 6 & 7 & 8 & 9 & 10 & 11 & 12 & 13 & 14 & 15 \\
\hline \multirow{16}{*}{ 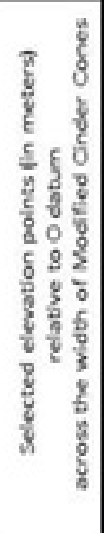 } & -4767 & -4315 & -4386 & -4007 & 4643 & -4842 & 921 & 2865 & .4335 & -4031 & 934 & -3765 & -4320 & 544 & .3525 \\
\hline & 4700 & -4276 & -4362 & -3922 & -4628 & -4814 & 1007 & 2958 & -4282 & -4009 & 1036 & .3735 & -4305 & 649 & -3488 \\
\hline & 4645 & -4255 & -4305 & -3886 & .4585 & -4848 & 1099 & 3084 & -4246 & -3990 & 1102 & -3723 & -4245 & 688 & .3477 \\
\hline & 4588 & -4128 & -4255 & -3821 & -4546 & -4866 & 1450 & 3254 & -4175 & -3964 & 1133 & -3707 & -4186 & 734 & -3450 \\
\hline & 4550 & -4037 & -4144 & -3756 & -4406 & -4844 & 1885 & 3237 & .3947 & -3901 & 1236 & -3635 & -4149 & 931 & -3407 \\
\hline & .4394 & -3915 & -3928 & -3628 & .3927 & -4590 & 2487 & 3438 & .3879 & 3990 & 1410 & -3250 & .3857 & 408 & .3229 \\
\hline & -5442 & -5246 & -5402 & -4293 & -5996 & -5948 & 1255 & 2481 & -5457 & -4090 & 378 & -4854 & -5062 & .50 & -4009 \\
\hline & 5346 & -4737 & -4831 & -4053 & -5613 & -5831 & 1623 & 2533 & -5214 & -4045 & 595 & -4158 & -4201 & 211 & $.37 \mathrm{ss}$ \\
\hline & -5580 & -4965 & -5456 & -4236 & -5752 & -5903 & 965 & 2452 & -5500 & -4060 & 386 & -4843 & -4704 & -53 & -4023 \\
\hline & 4306 & -3876 & -4663 & .3548 & -4161 & -4638 & 2122 & 3094 & -4798 & -3880 & 1303 & -3295 & -3918 & 400 & -3113 \\
\hline & .4343 & -4065 & -4050 & .3673 & -4344 & -4774 & 1875 & 3438 & -3818 & -3961 & 1100 & -3625 & -4117 & 825 & -3160 \\
\hline & 4572 & -4135 & -3951 & -3719 & -4500 & -4812 & 1674 & 3478 & -4096 & -3990 & 1000 & -3727 & -4146 & 782 & -3205 \\
\hline & -4660 & -4175 & .4080 & .3785 & .4518 & -4846 & 1485 & 3451 & -4226 & -4010 & 983 & -3841 & $-416 ?$ & 746 & .3259 \\
\hline & -4618 & -4205 & -4179 & -3872 & -4528 & -4884 & 1464 & 3304 & -4287 & -4025 & 965 & -3894 & -4212 & 724 & -3306 \\
\hline & 4693 & & .4370 & -3936 & 4538 & -4900 & 1370 & 3301 & .4354 & -4050 & 950 & -3900 & -4227 & 698 & .3447 \\
\hline & & & & & & -4936 & & 3133 & & & & -3916 & & 669 & \\
\hline
\end{tabular}

\section{Representation of Data}

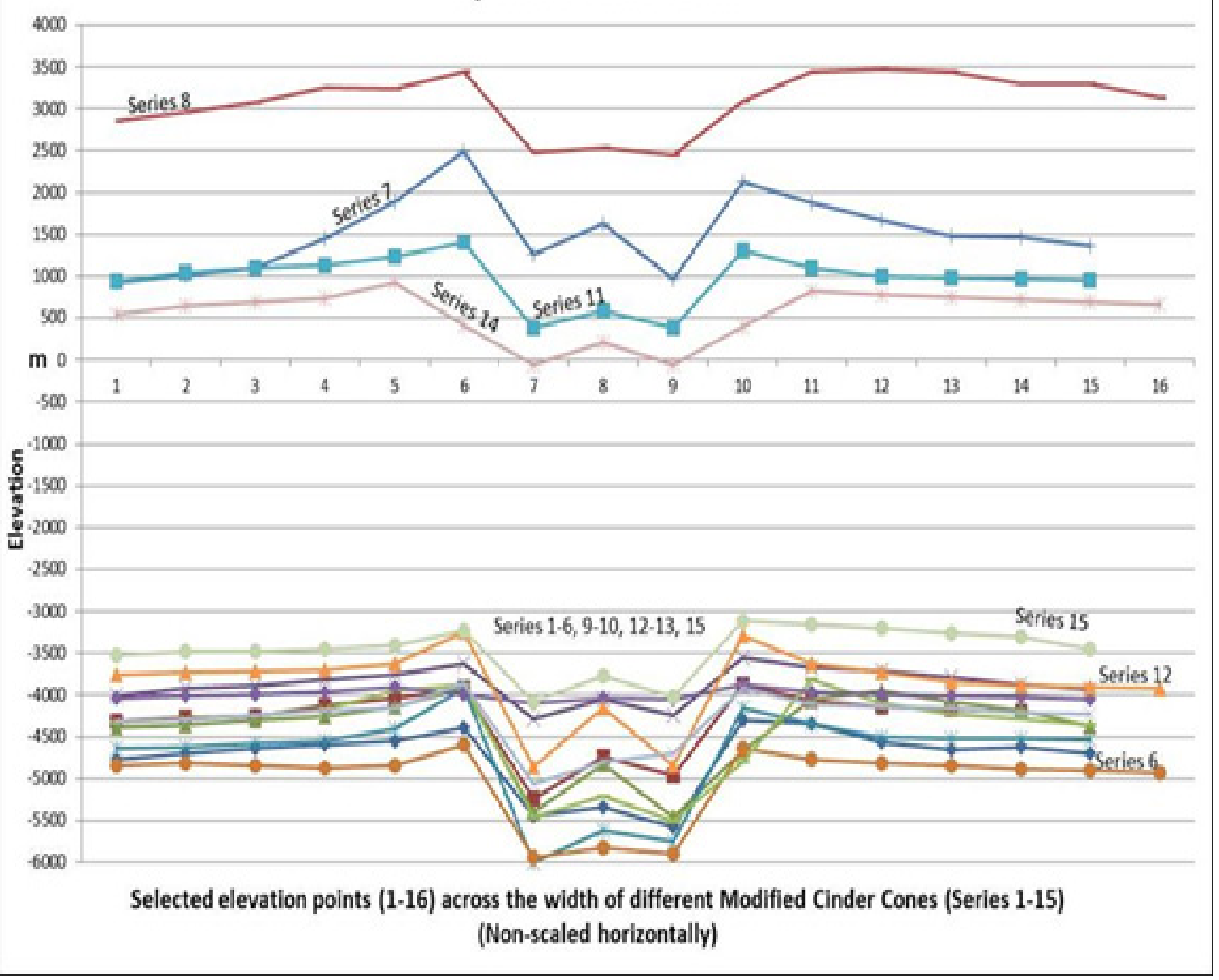

Figure 17: Topography and topographic location of different Modified Cinder Cones (MCC) with respect to 0 datum on Mars. The measurements of elevation (from 1 to 15) are more or less symmetrically spaced across the width of each modified cinder cone, but the width of cones is not constant throughout. To know details of diameter of summit, width of cone, subsurface depth of the summit and height of cone of each series of MCC see Figure 18.

Citation: Khaled Ak Ouda* and Nadia Af Sharara. Smaller Mountain Volcanoes on Mars: Cinder Cones. Op Acc J Bio Sci \& Res 5(5)-2020. 


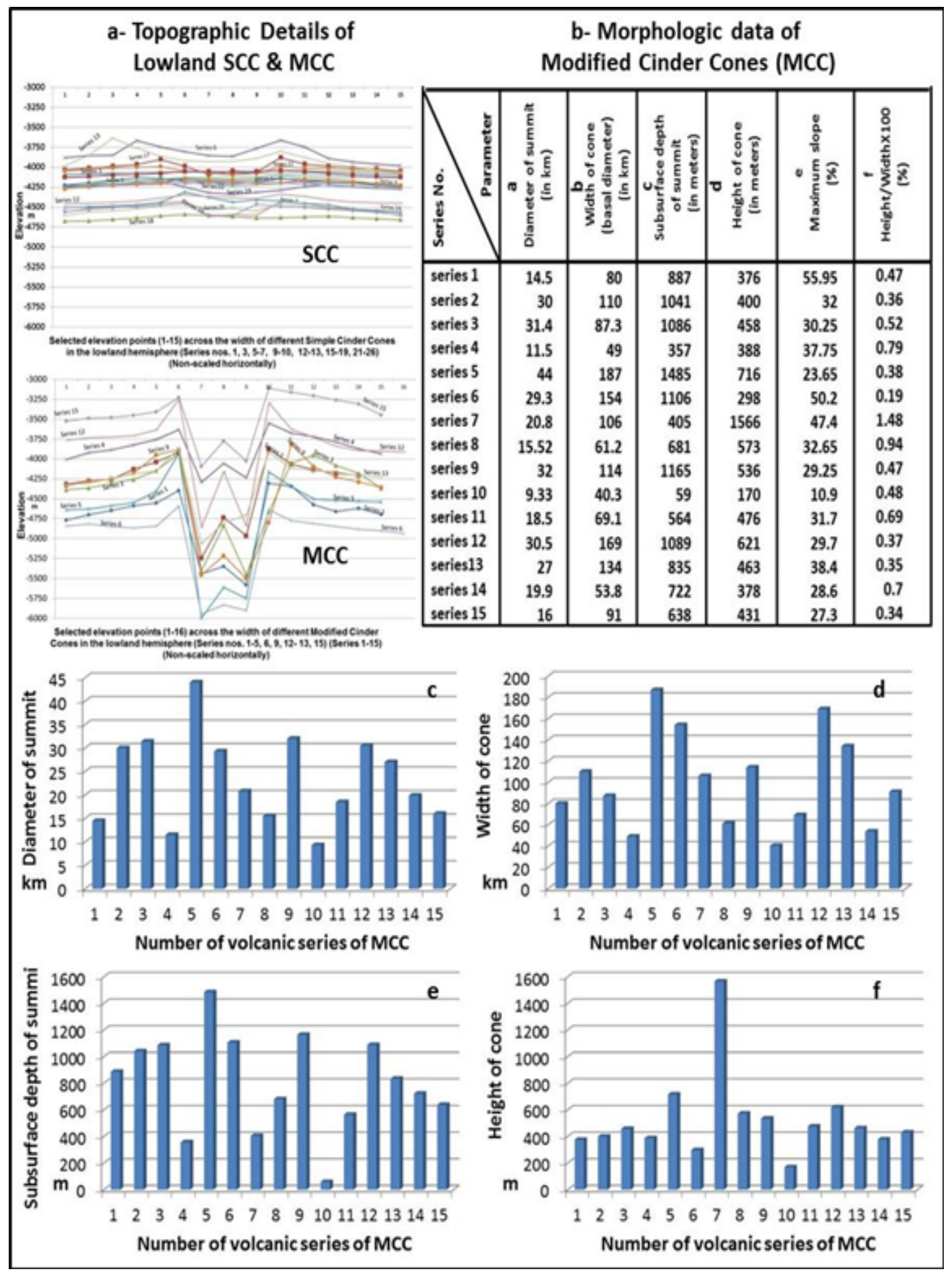

Figure 18: a-Cross sections of lowland Cinder Cones (below 0 datum level) showing topographic details of SCC (a) and MCC (b). Notice in a that the subsurface depth of summit is almost smaller than the height of cone, whereas in $b$ the subsurface depth of summit is exclusively larger than the height of cone and showing a parasitic lava dome erupted from the central vent or an upheaval bottom floor. $b$-f-Data and representation of morphologic features of Modified Cinder Cones (MCC) on Mars; $c$ - diameter of summit (in km); $d$ - width of cone (base diameter, in $\mathrm{km}$ ); $\mathrm{e}$ - subsurface depth of summit below ground surface (in meters); $f$ - height of cone above ground surface (in meters). For elevation data of different cinder cones see Figures 6, 7 and 15.

Citation: Khaled Ak Ouda* and Nadia Af Sharara . Smaller Mountain Volcanoes on Mars: Cinder Cones. Op Acc J Bio Sci \& Res 5(5)-2020. 


\section{a- Morphologic data of Parasitic Lava Domes inside the Modified Cinder}

\begin{tabular}{|c|l|l|l|l|l|l|l|l|l|l|l|l|l|l|}
\hline $\begin{array}{c}\text { Number of } \\
\text { series }\end{array}$ & 1 & 2 & 3 & 4 & 5 & 6 & 7 & 8 & 9 & 11 & 12 & 13 & 14 & 15 \\
\hline $\begin{array}{c}\text { Width of } \\
\text { lava dome } \\
\text { (in km) }\end{array}$ & 6 & 8.36 & 15 & 4.2 & 17.5 & 8.7 & 7 & 5 & 6.5 & 6.21 & 12.5 & 8.25 & 5.95 & 4.7 \\
\hline $\begin{array}{c}\text { Height of } \\
\text { lava domes } \\
\text { (in m) }\end{array}$ & 239 & 587 & 915 & 223 & 1270 & 290 & 651 & 81 & 375 & 212 & 1096 & 454 & 427 & 366 \\
\hline
\end{tabular}

\section{Graphic Correlation of Simple (SCC) and Modified (MCC) Cinder Cones}

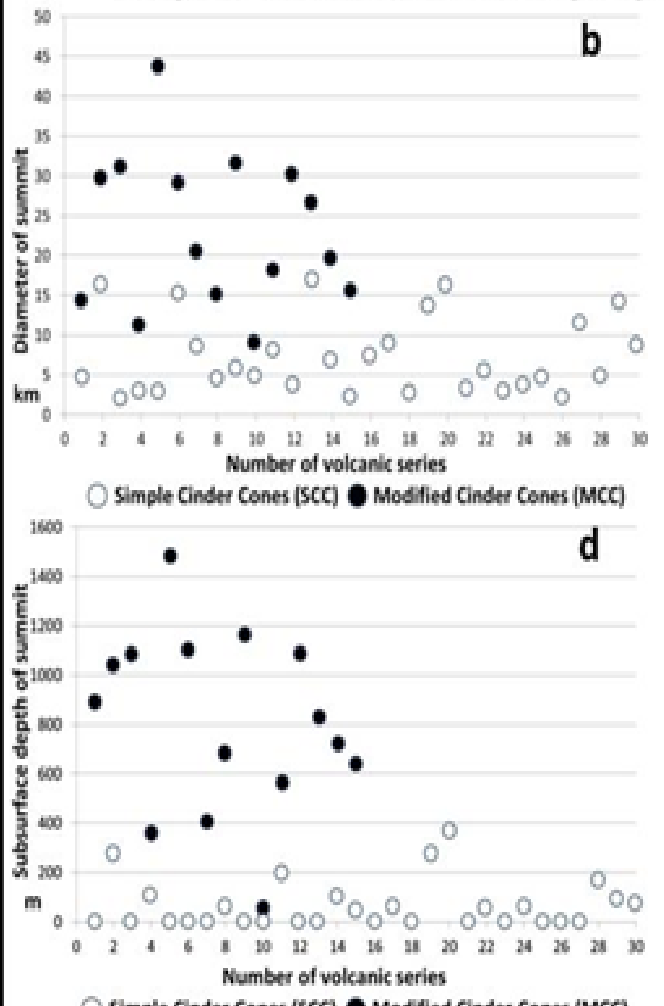

Simple Cinder Cones (SCC) $\bigcirc$ Modified Cinder Cones (MCC)

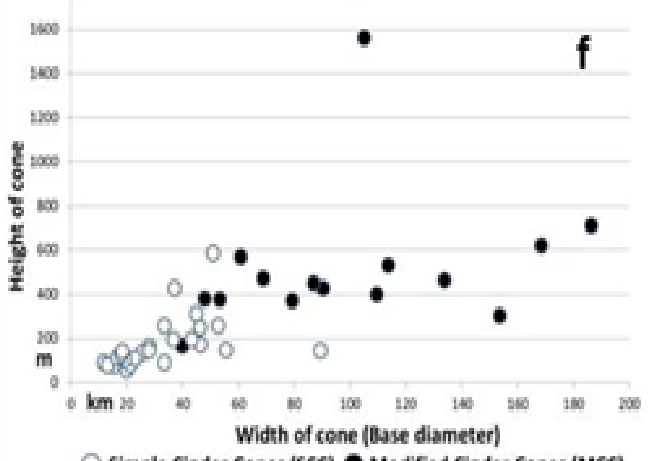

Simple Cinder Cones (SCC) $\bigcirc$ Modified Cinder Cones (MCC)

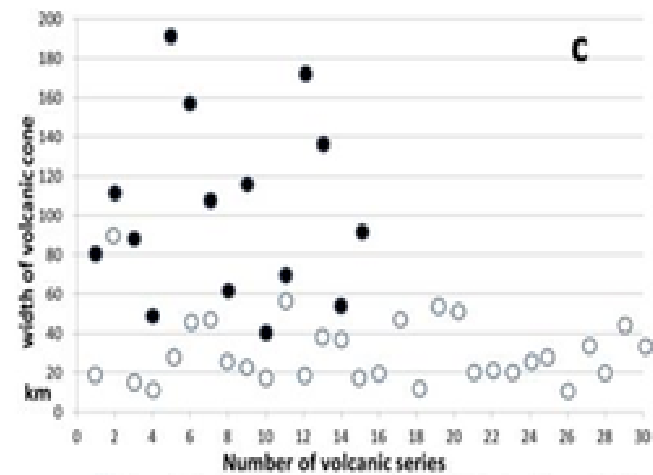

Simple Cinder Cones (SCC) O Modified Cinder Cones (MCC)

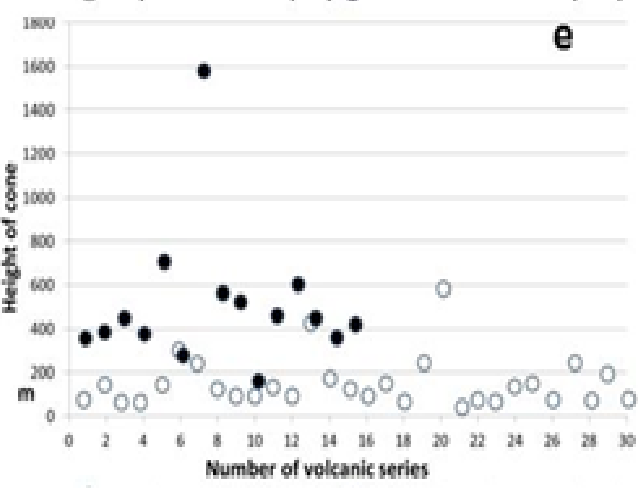

Simple Cinder Cones (scC) - Modified Cinder Cones (MCC)

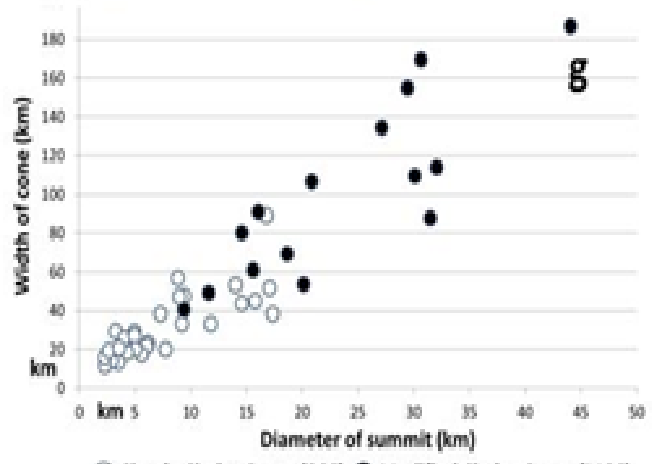

Simple Cinder Cones (SCC) Modified Cinder Cones (MCC)

Figure 19: a-Morphologic data of parasitic lava domes which ejected from the central vent of the modified cinder cones after re-filling of magma chamber below the pre-existing cones. $b$-g-Graphic representations between Simple Cinder Cones (SCC) and Modified Cinder Cones (MCC) showing correlation of different morphologic parameters, $b$-diameter of summit, $c$ - width of volcano (basal diameter), $d$ - subsurface depth of summit below ground surface, $e$ - height of cone, $f$ - height of cone versus width of cone, $g$ - width of cone (basal diameter) versus diameter of summit.

Citation: Khaled Ak Ouda* and Nadia Af Sharara. Smaller Mountain Volcanoes on Mars: Cinder Cones.

Op Acc J Bio Sci \& Res 5(5)-2020. 


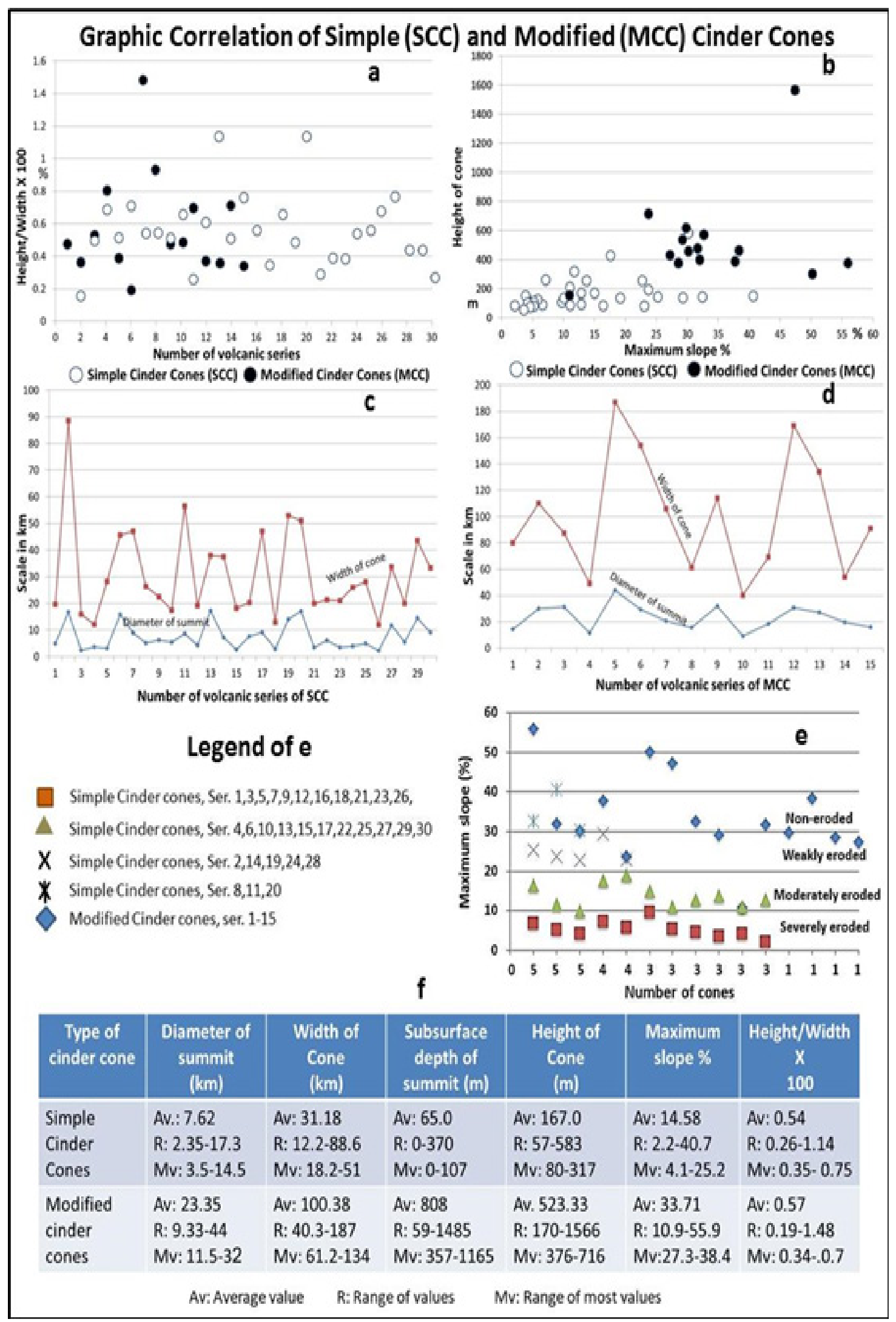

Figure 20: $a-b$-Graphic representations of height/width $x 100$ and height of cone versus maximum slope (\%) between SCC and MCC. $c$ - $d$ Correlation of diameter of summit (in $\mathrm{Km}$ ) and width of cone (basal diameter) in both typed of cones to show the intimate relationship between both parameters e-Maximum slope (\%) in different SCC and MCC. Note the effect of rate of erosion on the differentiation of the SCC into four groups of different maximum slopes. $f$ - Table showing correlation of morphologic data between SCC and MCC

Citation: Khaled Ak Ouda* and Nadia Af Sharara. Smaller Mountain Volcanoes on Mars: Cinder Cones. Op Acc J Bio Sci \& Res 5(5)-2020. 
decreases with increase of rate of erosion. It varies from $2.2 \%$ to $40.7 \%$ with most values range between $4.1 \%$ and $25.2 \%$, and an average value of $14.58 \%$, corresponding to a height varying from $57 \mathrm{~m}$ to $583 \mathrm{~m}$, with most values range between $80 \mathrm{~m}$ and $317 \mathrm{~m}$ and an average value of $167 \mathrm{~m}$. Three different rates of erosion could be recognized in the simple cinder cones in the northern hemisphere; severely eroded cones with a maximum slope less than $10 \%$ at or near the northern ice-cap, moderately eroded cones with a maximum slope lying between $10 \%$

\section{Parasitic Cinder Cones}

Beside the independent landforms the simple cinder cones occur as parasitic landforms inside the larger caldera craters in both northern and southern hemispheres of Mars. When occurring parasitically inside calderas, they are either intruding the peripheral side of the bottom surface of caldera from a peripheral vent (Figure 1j-1l) or occurring at the central vent of pre-existing large caldera where they represent a younger re-eruption of pyroclastic material after re-filling of the underlying magma chamber (Figure 10a-10g; Figure 11h-110). The ejected material started after the complete cession of volcanic eruption of the host caldera. The hosting caldera have a crater ranging in diameter from $13.6 \mathrm{~km}$ to $63 \mathrm{~km}$ and a total width ranging from $23.2 \mathrm{~km}$ to $85 \mathrm{~km}$. The new volcanic materials which are exclusively pyroclastic landed at the central vent of caldera building up a simple cone to a peak on the bottom floor of the caldera.

Correlation between the independent and parasitic simple cinder cones reveals that the parasitic cones possess a very small width and a very large height in contrast to the independent ones. The height of parasitic simple cones in larger calderas ranges in different studied volcanic series between $157 \mathrm{~m}$ and $841 \mathrm{~m}$ above the bottom surface of caldera, with most values lying between $253 \mathrm{~m}$ and $685 \mathrm{~m}$ and an average value of $464 \mathrm{~m}$ versus $167 \mathrm{~m}$ in the independent simple cones (Figure 12). The width of parasitic cones, on the other hand, ranges between 3.74 $\mathrm{km}$ and $18.6 \mathrm{~km}$, with most values lying between $4 \mathrm{~km}$ and $15 \mathrm{~km}$, and an average width of $8.19 \mathrm{~km}$ versus 31.18 $\mathrm{km}$ in the independent simple cones. The maximum slope is accordingly higher in parasitic cones (Av. $23 \%$ ) than in independent simple cones (Av. 14.58\%).

The difference between independent and parasitic simple cones is essentially due to the fact that lava of large degrees of liquidity when it is erupted into vast unlimited surfaces, it tends to spread over large areas while its height is greatly reduced, which causes the formation of a volcanic cone with a large base and a little height. However, if this lava was emitted in limited areas within the caldera craters, it tends to flow vertically upwards to compensate for the limited horizontal direction which is restricted by the host caldera walls.

No simple cinder cones are encountered along the flanks of major shield volcanoes of the Tharsis Montes and Olympus Mons. However, the northern and southern flows of the Alba Mons which can be traced as far north as $61^{\circ}$ $\mathrm{N}$ and far south as $26^{\circ} \mathrm{N}$ are marked by wide eruptions of clusters of simple as well as modified cinder cone volcanoes.

\section{Modified Cinder Cones (Mcc)}

These cinder cones are relatively large cone-shaped volcano characterized by having very steep sides and possessing a large, deep, bowel-shaped summit crater around a central vent beside a wide peripheral vent along the lower flanks of the cones (Figure 13a-13g; Figure 14h-14n). The depth of summit crater is much more in this type than in the simple cones. In the majority of representatives of this type the bottom surface of the summit crater is marked by the re-eruption of a younger phase of viscous lava flow from the central vent leading to the formation of volcanic dome over the central vent (Figure 15a-15e; Figure 16f-16j). Criteria of eruption of less viscous lava flow with water vapor and iron oxides through the lower flanks through the wide peripheral vent are evident in most modified cinder cones

Like the simple cinder cones, the volcanic series belonging to the modified cinder cones are widely distributed in the low-lying topographic areas (below 0 datum level) of the northern hemisphere of Mars particularly in the area lying between latitudes $40^{\circ} \mathrm{N}$ and $75^{\circ} \mathrm{N}$. In the southern highland hemisphere above 0 datum level, they occur individually or in clusters particularly between latitudes $22^{\circ}$ $\mathrm{S}$ and $30^{\circ} \mathrm{S}$. However, the modified cones occupy a relatively wider range of topographic levels than the simple cones, between elevations $-6000 \mathrm{~m}$ and $-3000 \mathrm{~m}$ in the northern hemisphere and between elevations 0 and $+4000 \mathrm{~m}$ in the southern hemisphere (Figure 17).

The modified cinder cones differ from the simple cinder cones by having a larger and deeper bowel-shaped summit crater extending below the ground surface level, a higher and wider cone, a central vent beside a wide peripheral vent, and the presence of a younger parasitic volcanic dome at the bottom floor of the collapsed summit (Figure 15a-15e; Figure 16f-16j). An additional eruption of younger lava flow through the peripheral vent along the lower flanks occurs in most cones. Cross sections of lowland cinder

cones (below 0 datum level) show that the subsurface depth of summit of the simple cinder cones is almost 
smaller than the height of cone, whereas in the modified cones the depth of summit is exclusively larger than the height of cone and extends much deeper with steep sides below the ground surface where it is subjected to the intrusion of a younger intrusion of parasitic lava dome at the bottom floor of the summit (Figure 18a). The diameter of summit crater varies in different studied volcanic series belonging to the modified cinder cones from $9.33 \mathrm{~km}$ to 44 $\mathrm{km}$, with most values lying between $11.5 \mathrm{~km}$ and $32.0 \mathrm{~km}$ and an average diameter of $23.35 \mathrm{~km}$, corresponding to an average diameter of $7.62 \mathrm{~km}$ in the simple cinder cones. The width (basal diameter) of the cones varies from $40.3 \mathrm{~km}$ to $187 \mathrm{~km}$, with most values lying between $61.2 \mathrm{~km}$ and 132 $\mathrm{km}$ and an average width of $100.38 \mathrm{~km}$, corresponding to an average width of $31.18 \mathrm{~km}$ in the simple cinder cones. The height of the modified cones varies in different studied series from $170 \mathrm{~m}$ to $1566 \mathrm{~m}$, with the majority of values lying between $376 \mathrm{~m}$ and $716 \mathrm{~m}$ and an average value of $523.3 \mathrm{~m}$, corresponding to an average height of $167 \mathrm{~m}$ in the simple cinder cones. The subsurface depth (below ground surface level) of the summit crater varies from $59 \mathrm{~m}$ to $1485 \mathrm{~m}$, with the majority of values lying between $357 \mathrm{~m}$ and $1165 \mathrm{~m}$ and an average value of $808 \mathrm{~m}$ (Figure 18b-18f; Figure 19a-19b). Correlation of the morphologic features between the simple cinder cones and modified cinder cones is given in (Figure 19c-19h and Figure 20a-20f).

The maximum slope of the modified cinder cones is markedly higher (Av. 33.7\%) than that of the simple cinder cones (Av. $14.58 \%$ ), corresponding to the higher height of the modified cones (Av. $523.33 \mathrm{~m}$ ) versus the simple cones (Av. $167 \mathrm{~m}$ ) (Figure 20e-20f). However, the parameter height/width $\times 100$ shows more or less equivalent values between the modified (Av. 0.57) and the simple cinder cones (Av. 0.54) although the latter cones show intensive to moderate erosion relative to the modified cones. This would imply that the morphological differences between both types of cones are not related to differences in rate of erosion, but due to differences in the amount of the erupting lava, the pressure of eruption of this lava from the vent and the area of the eruption above the surface. (base diameter, in $\mathrm{km}$ ); e- subsurface depth of summit below ground surface (in meters); $f$ - height of cone above ground surface (in meters). For elevation data of different cinder cones see (Figures 6, 7 \& 15).

The effect of erosion on the modified cinder cones is weak if not none as deduced from their higher maximum slope which ranges in most representatives between $27 \%$ and $38 \%$ with an average value of $33.7 \%$. Those which occur together with the simple cinder cones in the lowlands in the northernmost hemisphere near the northern ice cap vary from weakly eroded to non-eroded. The maximum slope of these northern cones ranges in most representatives between $27.3 \%$ and $38.4 \%$, and with an average maximum slope of $33.2 \%$, corresponding to a height ranging in most cones between $376 \mathrm{~m}$ and $536 \mathrm{~m}$, and with an average height of $441.5 \mathrm{~m}$. Since the difference in maximum slope reflects difference in duration of time of erosion it can be concluded that the modified cinder cones in the northern hemisphere are distinctly younger than the simple cinder cones in the same area which show a strong evidence of severe to weak erosion with varying rates leading to variable heights and maximum slopes of cones (see above).

In the highlands of the southern hemisphere, on the other hand, the modified cinder cones are almost noneroded and showing a maximum slope ranging between $28.6 \%$ and $55.9 \%$, and with an average maximum slope of $35.08 \%$, corresponding to a height ranging from $378 \mathrm{~m}$ and $1566 \mathrm{~m}$, and with an average height of $748.25 \mathrm{~m}$ (Figure 20e). Thus, the age of the cinder cones is not synchronous on Mars; the simple cones in the northern hemisphere represent older stages of volcanic eruption while the modified cones in the same area represent relatively younger stages of volcanic eruption. Those in the southern hemisphere (both simple and modified cones) are much younger than those in the northern hemisphere.

The parasitic volcanic domes at the central vent of the summit crater of the modified cinder cones are formed by a younger phase of eruption of a viscous lava that solidified immediately above the central vent of the pre-existing large cinder cones (Figure 16a-16e; Figure 17f-17j). They vary in height from $81 \mathrm{~m}$ to $1270 \mathrm{~m}$, with the majority of values in the studied series lying between $223 \mathrm{~m} 651 \mathrm{~m}$, and in width from $4.2 \mathrm{~km}$ to $17.5 \mathrm{~km}$, with most values lying between $4.2 \mathrm{~m}$ and $8.4 \mathrm{~m}$ (Figure 19a). However, very few representatives of the modified cones which do not possess parasitic volcanic

The modified type of cinder cones has no counterparts on Earth. According to the definition of the US Geological Survey the cinder cone volcanoes are fairly small, generally only 300 feet $(91 \mathrm{~m})$ tall and not rising more than 1200 feet (366 m). This definition can only be applied to the simple cinder cones, not to the modified cones as described here on Mars. No modified cinder cones are recorded along the flanks of the shield volcanoes of the Tharsis Montes except of the Olympus Mons where one modified cinder cone (Karzok crater) erupts along its upper flanks. However, both types (simple and modified) of cinder cones are commonly found along the extreme northern and southern flows of the Alba Mons, suggesting that both types of cinder cone 
volcanoes have continued eruption younger than the age of the flows of Alba Mons 5.

\section{Conclusion}

The cinder cones on Mars show a variable height, width (basal diameter), diameter of summit and subsurface depth of summit below ground surface, as well as the presence or absence of second post cinder cone re-eruption of lava at the bottom of the summit. They are much wide by 40 to 50 times than terrestrial cones. They occur either independently or as parasitic landforms erupted at the bottom floor of larger pre-existing calderas and along the flanks of some shield volcanoes. When occurring independently they form isolated massive fields in the lowlands of the northern hemisphere where they show evidence of erosion with varying rates, whereas in the highlands of the southern hemisphere they occur in clusters with no or little rate of erosion. This would suggest that cinder cones are not synchronous on Mars

Two different morphological types of cinder cones of different relative ages are distinguished on the Martian surface;

1. Older, Simple Cinder Cones (SCC) with a narrow peripheral vent, a closed central vent and a small, shallow summit crater (Av. diameter of summit is $7.62 \mathrm{~km}$ ) without post-cone eruption of younger phase of volcanic lava at the bottom floor of summit. The average width of these cones (basal diameter) Is $31.18 \mathrm{~km}$, whereas their average height is $167.0 \mathrm{~m}$. The depth of the summit of the majority of cones is almost higher than the ground surface level and normally less than the height of cone. Three different rates of erosion could be recognized in the simple cinder cones in the northern hemisphere; severely eroded cones (maximum slopes less than $10 \%$ ), moderately eroded cones (maximum slopes ranging between $10 \% 20 \%$ ); and weakly eroded cones (maximum slopes ranging between $20 \%$ and $30 \%$ ). In the southern hemisphere the simple cones are either weakly eroded or non-eroded where they show maximum slopes lying between $20 \%$ and $40 \%$. The difference in maximum slope reflects difference in duration of time of erosion; the severely eroded cones seem to be the oldest cones while the weakly to non-eroded cones represent the youngest simple cinder cones.

2. Younger, Modified Cinder Cones (MCC) characterized by having a central vent beside a wide peripheral vent and a larger, steep-sided, bowel-shaped summit crater (Av. diameter of summit is $23.35 \mathrm{~km}$ ) which extends below the ground surface level by $59 \mathrm{~m}$ to $1485 \mathrm{~m}$ and shows a postcone eruption of a younger parasitic volcanic dome at the bottom floor. These cones are considerably higher (Av. height $523.3 \mathrm{~m}$ ) and wider (Av. width $100.38 \mathrm{~km}$ ) than the simple cinder cones. The parasitic volcanic dome is formed by a younger phase of re-eruption of viscous lava that solidified immediately above the central vent of the pre-existing large cinder cones. However, very few representatives of the modified cones which do not possess parasitic volcanic domes exhibit upheaval bottom floor of the summit crater due to moving of the underlying lava flow. The modified cinder cones are either weekly eroded or non-eroded in the northern hemisphere, whereas in the southern hemisphere they are almost non-eroded. Their maximum slope is markedly higher (Av. $33.7 \%$ ) than that of the simple cinder cones (Av. $14.58 \%$ ). This would suggest that the modified cones represent younger stages of volcanic eruption relative to the simple cinder cones

The parasitic cinder cones are either intruding the bottom surface of large calderas from a peripheral vent or occurring at the central vent of pre-existing large caldera where they represent a younger re-eruption of pyroclastic material after re-filling of the underlying magma chamber. They possess a small width, a large height and a higher maximum slope as compared to independent cones. The average height of parasitic cones in larger calderas is $464 \mathrm{~m}$ versus $167 \mathrm{~m}$ in the independent simple cones. The average width of parasitic cones, on the other hand is $8.19 \mathrm{~km}$ versus $31.18 \mathrm{~km}$ in the independent simple cones. The maximum slope is accordingly higher in parasitic cones (Av. $23 \%$ ) than in independent simple cones (Av. $14.58 \%$ ) due to the fact that lava of large degrees of liquidity when re-erupted at the bottom surface of pre-existing caldera, it tends to flow vertically upwards to compensate for the limited horizontal direction which is restricted by the host caldera walls.

\section{Acknowledgement}

The authors wish to express their gratitude to the Management of Assiut University for providing Lab facilities necessary for the completion of this study. Deep thanks are also due to the reviewers for their insightful reviews and valuable comments on this manuscript.

\section{Declarations}

Funding: No funding

Conflicts of interest: No conflicts 


\section{References}

1. Settle M (1979) The structure and emplacement of cinder cone fields. Am J Sci 279: 1089-1107.

2. Wood CA (1980a) Morphometric evolution of cinder cones. J Volcanol Geotherm Res 7: 387-413.

3. USGS Photo glossary; Cinder Cones (2007).

4. Fornaciai A, Favalli M, Karátson D, Tarquini S, Boschi E (2012) Morphometry of scoria cones, and their relation to geodynamic setting: a DEM-based analysis. J Volcanol Geotherm Res 217-218: 56-72.

5. Wood CA (1979) Cinder cones on Earth, Moon and Mars. Lunar Planet Sci X: 1370-1371.

6. Wood CA (1980b) Morphometric analysis of cinder cone degradation. J Volcanol Geotherm Res 8: 137-160.

7. Pioli L, Azzopardi BJ, Cashman KV (2009) Controls on the explosivity of scoria cone eruptions: magma segregation at conduit junctions. J Volcanol Geotherm Res 186: 407-415.

8. Fodor E, Brož P (2015) Cinder Cone. Encyclopedia of Planetary Landforms.

9. Gregg TKP, Shockey K (2008) Distribution of small volcanic constructs on Earth, Mars, Venus and the Moon: comparisons and contrasts. Geol Soc Am Abstr Program 40(6): 114.

10. Wichman RW, Schultz PH (1989) Sequence and mechanisms of deformation around the Hellas and Isidis Impact Basins on Mars. J. Geophys. Res. 94: p.17343.

11. Wilson L, and Head JW (1994) Review and analysis of volcanic eruption theory and relationships to observed landforms, Rev. Geophys 32: 221263.

12. Keszthelyi L, Jaeger W, McEwen A, Tornabene L, Beyer RA, et al. (2008) High Resolution Imaging Science Experiment (HiRISE) images of volcanic terrains from the first 6 months of the Mars Reconnaissance Orbiter primary science phase. J Geophys Res 113: E04005.

13. Meresse S, Costard F, Mangold N, Masson P, Neukum G, et al. (2008)
Formation and evolution of the chaotic terrains by subsidence and magmatism: hydraotes Chaos, Mars. Icarus 194: 487-500.

14. Hauber E, Bleacher J, Gwinner K, Williams D, Greeley R (2009) The topography and morphology of low shields and associated landforms of plains volcanism in the Tharsis region of Mars. J Volcanol Geotherm Res 185: 69-95.

15. Lanz JK, Wagner R, Wolf U, Kröchert J, Neukum G (2010) Rift zone volcanism and associated cinder cone field in Utopia Planitia, Mars. J Geophys Res 115: E12019.

16. Brož P, Hauber E (2012) A unique volcanic field in Tharsis, Mars: pyroclastic cones as evidence for explosive eruptions. Icarus 218: 88-99.

17. Plescia JB (1980) Cinder cones of Isidis and Elysium. NASA Tech. Memo 82385: 263-265

18. Bleacher JE, Glaze LS, Greeley R, Hauber E, Baloga SM, et al. (2009) Spatial and alignment analyses for a field of small volcanic vents south of Pavonis Mons and implications for the Tharsis province, Mars. J Volcanol Geotherm Res 185: 96-102.

19. Brož, P, Čadek O, Hauber E, Rossi AP (2015a) Scoria cones on Mars: Detailed investigation of morphometry based on high-resolution digital elevation models, J. Geophys. Res. Planets: 120 (9): 1512-1527.

20. Brož, P, Čadek O, Hauber E, Rossi AP (2014) Shape of scoria cones on Mars: Insights from numerical modeling of ballistic pathways, Earth Planet. Sci. Lett 406: 14-23.

21. Lanz JK, Saric MB (2009) Cone fields in SW Elysium Planitia: Hydrothermal venting on Mars?. J Geophys Res 114(2).

22. Ghent RR, Anderson SW, Pithawala TM (2012) The formation of small cones in Isidis Planitia, Mars through mobilization of pyroclastic surge deposits. Icarus 217: 169-183.

23. Gilichinsky M, Demidov N, Rivkina E (2015) Morphometry of volcanic cones on Mars in perspective of Astrobiological Research Michael. International Journal of Astrobiology 14 (4): 537-545.

24. Head JW (2007) The Geology of Mars: New Insights and Outstanding Questions in The Geology of Mars: Evidence from Earth-Based Analogs, Chapman, M., Ed; Cambridge University Press: Cambridge UK, p. 10.

*Corresponding author: Khaled Ak Ouda,Email: Khaledabdelkader_ouda@yahoo.com; kh.ouda@aun.edu.eg

\author{
Next Submission with BGSR follows: \\ - Rapid Peer Review \\ - Reprints for Original Copy \\ - E-Prints Availability \\ - Below URL for auxiliary Submission Link: https://biogenericpublishers.com/submit-manuscript/
}

